\title{
Gas/particle partitioning of water-soluble organic aerosol in Atlanta
}

\author{
C. J. Hennigan ${ }^{1,}$, M. H. Bergin ${ }^{1,2}$, A. G. Russell ${ }^{1}$, A. Nenes ${ }^{2,3}$, and R. J. Weber ${ }^{2}$ \\ ${ }^{1}$ School of Civil and Environmental Engineering, Georgia Institute of Technology, Georgia, USA \\ ${ }^{2}$ School of Earth and Atmospheric Sciences, Georgia Institute of Technology, Georgia, USA \\ ${ }^{3}$ School of Chemical and Biomolecular Engineering, Georgia Institute of Technology, Georgia, USA \\ * now at: The Center for Atmospheric Particle Studies, Carnegie Mellon University, Pittsburgh, Pennsylvania, USA
}

Received: 29 October 2008 - Published in Atmos. Chem. Phys. Discuss.: 8 January 2009

Revised: 6 April 2009 - Accepted: 18 May 2009 - Published: 4 June 2009

\begin{abstract}
Gas and particle-phase organic carbon compounds soluble in water (e.g., WSOC) were measured simultaneously in Atlanta throughout the summer of 2007 to investigate gas/particle partitioning of ambient secondary organic aerosol (SOA). Previous studies have established that, in the absence of biomass burning, particulate WSOC $\left(\mathrm{WSOC}_{p}\right)$ is mainly from secondary organic aerosol (SOA) production. Comparisons between $\mathrm{WSOC}_{p}$, organic carbon (OC) and elemental carbon (EC) indicate that $\mathrm{WSOC}_{p}$ was a nearly comprehensive measure of SOA in the Atlanta summertime. $\mathrm{WSOC}_{p}$ and gas-phase WSOC (WSOC $g$ ) concentrations both exhibited afternoon maxima, indicating that photochemistry was a major route for SOA formation. An additional nighttime maximum in the $\mathrm{WSOC}_{g}$ concentration indicated a dark source for oxidized organic gases, but this was not accompanied by detectable increases in $\mathrm{WSOC}_{p}$. To study SOA formation mechanisms, WSOC gas/particle partitioning was investigated as a function of temperature, $\mathrm{RH}$, $\mathrm{NO}_{\mathrm{x}}, \mathrm{O}_{3}$, and organic aerosol mass concentration. No clear relationship was observed between temperature and partitioning, possibly due to a simultaneous effect from other temperature-dependent processes. For example, positive temperature effects on emissions of biogenic SOA precursors and photochemical SOA formation may have accounted for the observed similar proportional increases of $\mathrm{WSOC}_{p}$ and $\mathrm{WSOC}_{g}$ with temperature. Relative humidity data indicated a linear dependence between partitioning and predicted fine particle liquid water. Lower $\mathrm{NO}_{\mathrm{x}}$ concentrations were associated with greater partitioning to particles, but WSOC partitioning had no visible relation to $\mathrm{O}_{3}$ or fine particle OC mass concentration. There was, however, a relationship between WSOC partitioning and the $\mathrm{WSOC}_{p}$ concentration,
\end{abstract}

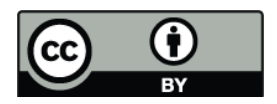

Correspondence to: R. Weber (rweber@eas.gatech.edu) suggesting a compositional dependence between partitioning semi-volatile gases and the absorbing organic aerosol. Combined, the overall results suggest two dominant SOA formation processes in urban Atlanta during summer. One was the photochemical production of SOA from presumably biogenic precursors that increased with the onset of sunrise and peaked in the afternoon. The other, which showed no apparent diurnal pattern, involved the partitioning of semi-volatile gases to liquid water, followed by heterogeneous reactions. The co-emission of water vapor and biogenic VOCs from vegetation may link these processes.

\section{Introduction}

The gas/particle partitioning of oxidized semi-volatile organic compounds (SVOCs) is an integral process in the formation of secondary organic aerosol (SOA), making it one of the most important routes for producing fine atmospheric particles. At present, there is little data that characterizes the total gas/particle partitioning of ambient SOA, largely due to the plethora of species involved in partitioning and the highly complex nature of SOA. Ambient studies have, however, examined the partitioning of individual secondary organic compounds. For example, Matsunaga et al. (2005) simultaneously measured ten carbonyls in the gas and particle phases at a site near Tokyo, while Fisseha et al. (2006) made simultaneous measurements of four carboxylic acids in the gas and particle phases in Zurich. One limitation to these studies, and others like them, is that they characterize a very minor fraction of the total SOA (and hence, organic carbon aerosol (OC)) mass, so their behavior may not be representative of the SOA. Additionally, heterogeneous reactions may alter the condensed phase component to forms difficult to detect, which would then not be considered in single component analysis partitioning studies.

Published by Copernicus Publications on behalf of the European Geosciences Union. 
Smog chamber experiments have described the gas/particle partitioning behavior of total SOA generated from a given volatile organic compound (VOC) or VOC mixture. Evidence from chamber experiments suggests that the partitioning of SVOCs between gas and particle phases is highly dependent upon the organic aerosol mass (Odum et al., 1996; Odum et al., 1997; Hoffmann et al., 1997), consistent with SOA gas/particle partitioning models (e.g., Pankow, 1994). The strong temperature dependence of SOA formation in smog chamber experiments is also consistent with partitioning theory (Takekawa et al., 2003). The translation of these studies to the ambient atmosphere remains a challenge, as current models employing these mechanisms systematically under-predict ambient SOA concentrations (de Gouw et al., 2005). The cause(s) of this discrepancy is still not clear, and is not necessarily the result of uncertainties in the partitioning model: other factors could be responsible, including additional SOA precursors not currently considered (Goldstein and Galbally, 2007; Volkamer et al., 2009). The lack of ambient data that may provide clear and comprehensive mechanistic insights into the SOA formation process inhibits an understanding of the exact causes for the modeling discrepancies.

In this study, we analyze the gas/particle partitioning of ambient SOA through extensive time-resolved measurements of water-soluble organic carbon compounds in the gas $\left(\mathrm{WSOC}_{g}\right.$ ) and particle (WSOC $p$ ) phases in summertime Atlanta. In making a bulk measurement like WSOC, chemical specificity related to individual compounds is lost, but instead a major fraction of the SOA, and hence, a large fraction of total OC mass, is characterized.

\section{Methods}

Ambient gas and particle measurements were conducted from 11 May-20 September 2007 on the Georgia Institute of Technology Campus, located near the center of Atlanta. The measurement platform was $\sim 30-40 \mathrm{~m}$ above ground, and the instruments were located in the rooftop laboratory of the Ford Environmental Science \& Technology Building.

$\mathrm{WSOC}_{p}$ measurements were conducted via a particleinto-liquid sampler (PILS) coupled to a Total Organic Carbon analyzer, a method which has been detailed by Sullivan et al. (2004). Briefly, particles with aerodynamic diameter less than $2.5 \mu \mathrm{m}$, selected using a non-rotating microorifice impactor (Marple et al., 1991), were collected into the liquid phase by a PILS (Orsini et al., 2003) operated at $15 \mathrm{~L} \mathrm{~min}^{-1}$. The aqueous sample was then transferred to a Total Organic Carbon (TOC) analyzer (GE Analytical) for the semi-continuous determination of the water-soluble fraction of the carbonaceous aerosol. Two studies have shown that this approach agrees to within $\sim 10 \%$ with $\mathrm{WSOC}_{p}$ extracted from integrated filters (Sullivan and Weber, 2006; Miyazaki et al., 2006). The TOC analyzer was operated with a six-minute integration time, the maximum sampling rate of the analyzer employed. Twice daily, the sample airstream was diverted through a filter to determine the organic carbon content of the collection water and any interference from VOCs potentially collected by the PILS. This dynamic blank was subtracted from sample organic carbon values to quantify the ambient concentration of $\mathrm{WSOC}_{p}$. The limit of detection was approximately $0.1 \mu \mathrm{g} \mathrm{C} \mathrm{m}^{-3}$ and the estimated uncertainty of the method is $\sim 10 \%$ (Sullivan et al., 2004).

$\mathrm{WSOC}_{g}$ concentrations were measured with a method similar to that of Anderson et al. (2008), but modified and configured for the present study. Sample air was pulled at $21 \pm 1 \mathrm{~L} \mathrm{~min}^{-1}$ through a Teflon filter for particle removal, and immediately entered a glass mist chamber (MC) (Cofer and Edahl, 1986) initially filled with $10 \mathrm{~mL}$ of ultra-pure ( $>18.0 \mathrm{M} \Omega$, low carbon) water. The MC, which was operated with a sample residence time of approximately $0.45 \mathrm{~s}$, efficiently collects gases with a Henry's Law constant greater than $10^{3} \mathrm{M} \mathrm{atm}^{-1}$ (Spaulding et al., 2002). The collection efficiency was tested using nitric acid, and found to be $95.1 \% \pm 2.1 \%$ (mean $\pm 1 \sigma$ ). One five-minute batch sample was collected every ten minutes using an automated valve to open and close flow from the MC to the vacuum pump. Once collected, the sample was analyzed by a Total Organic Carbon analyzer (GE Analytical). In between sample analyses, the carbon content of the $18.0 \mathrm{M} \Omega$ ultra-pure water was determined and the $\mathrm{MC}$ was rinsed with the ultra-pure water as well. The carbon content of the pure water was subtracted from the organic carbon content of the subsequent sample to quantify the organic carbon of the captured ambient organic gases.

Factory calibrations were performed on the two TOC analyzers used to measure $\mathrm{WSOC}_{p}$ and $\mathrm{WSOC}_{g}$, and sucrose standards were also periodically run over the full range (50-2000 ppb C) of expected liquid concentrations to verify proper analyzer accuracy throughout the measurement period.

Accurate determination of the concentrations measured with the MC depends on an accurate measure of the volume of water used to collect the sample. Consequently, water evaporation effects during sample collection need to be accounted for. Calibrations of water evaporation were performed using gravimetric analysis on three separate days ( $n$ total $=56$ ). It was found that evaporation was approximately constant, regardless of ambient temperature and relative humidity (RH) conditions. During the calibrations, ambient temperature exhibited a range of $18.5-32.4^{\circ} \mathrm{C}$ while ambient RH exhibited a range of 23-66\%. With an initial volume of $10 \mathrm{~mL}$, the ending volume after five minutes of sampling was $8.75 \mathrm{~mL} \pm 0.12 \mathrm{~mL}(1.4 \%)$ at the $95 \%$ confidence interval. Because the ambient temperature and RH conditions encountered during calibrations covered much of the range observed during sampling, the use of a constant ending water volume is assumed to be valid throughout the study period. At an air flow rate of $21 \mathrm{~L} \mathrm{~min}^{-1}$ and a five-minute 
sample integration time, the LOD for the $\mathrm{WSOC}_{g}$ measurement was $0.9 \mu \mathrm{g} \mathrm{C} \mathrm{m}^{-3}$. Based on uncertainties in the airflow $( \pm 5 \%)$, ending water volume $( \pm 1.4 \%)$, TOC analyzer uncertainty $( \pm 2 \%)$, and uncertainty in the TOC background concentration $( \pm 2 \%)$, the overall estimated uncertainty for the $\mathrm{WSOC}_{g}$ measurement is $7 \%$.

Measurements of aerosol organic carbon (OC) and elemental carbon (EC) were made with a Sunset Labs OCEC Field Analyzer (Sunset Laboratory Inc., Tigard, OR) in accordance with NIOSH method 5040 (NIOSH, 1996). The measurements consisted of a 45-min collection period followed by $15 \mathrm{~min}$ of analysis time. The data are not blankcorrected and may be systematically overestimated by about $0.5 \mu \mathrm{g} \mathrm{C} \mathrm{m}^{3}$ (Peltier et al., 2007). At a sampling time of $45 \mathrm{~min}$, the method uncertainty is estimated at $20 \%$ (Peltier et al., 2007). $\mathrm{NO}_{\mathrm{x}}$ concentrations measured via chemiluminescence were taken from the Georgia Department of Natural Resources (DNR) Ambient Monitoring Network (http://www.georgiaepd.org/air/amp/) site co-located with the aerosol measurements discussed above, while $\mathrm{O}_{3}$ data were taken from a Georgia DNR site approximately $5 \mathrm{~km}$ from the Georgia Institute of Technology campus.

Measurements were carried out for approximately 4.5 months, with intermittent periods for instrument maintenance/repair and calibrations, such that the total number of observations was equivalent to approximately 3 months of continuous sampling. As detailed above, the measurements were carried out at a high time resolution; six minutes for the $\mathrm{WSOC}_{p}$ measurement, a five-minute $\mathrm{WSOC}_{g}$ sample every $10 \mathrm{~min}$, and hourly for the $\mathrm{OC}$ and $\mathrm{EC}$ measurements. The high time resolution and extended length of the measurements resulted in the collection of extensive data sets that provided high statistical significance for the analyses performed ( $n=19049$ for $\mathrm{WSOC}_{p}, n=12298$ for $\mathrm{WSOC}_{g}$, $n=1478$ for OC and EC, the sample size for an averaged dataset corresponds to the instrument with lower sampling rate). This may provide insights into overall trends that would not have been detected with a shorter data set due to the many short-term factors that cause day-to-day variability in ambient SVOC and particle concentrations.

\section{Results and discussion}

\subsection{WSOC in Atlanta}

In the following analysis, infrequent periods of biomass burning influence were removed from the data set. For the entire summer, $\mathrm{WSOC}_{p}$ was in the range of $0.2-12.1 \mu \mathrm{g} \mathrm{C} \mathrm{m}^{-3}$ and had an average concentration of $3.3 \pm 1.8 \mu \mathrm{g} \mathrm{C} \mathrm{m}^{-3}$ (mean $\pm 1 \sigma$, for $n=19049$ ). $\mathrm{WSOC}_{p}$ was highly correlated with OC $\left(R^{2}=0.73\right)$ and the slope $(0.70 \mu \mathrm{g}$ $\mathrm{C} / \mu \mathrm{g} \mathrm{C}$ ) indicates that a high fraction of the $\mathrm{OC}$ was soluble and hence likely to be secondary. (Note, the results are based on a Deming linear regression that minimizes the distance

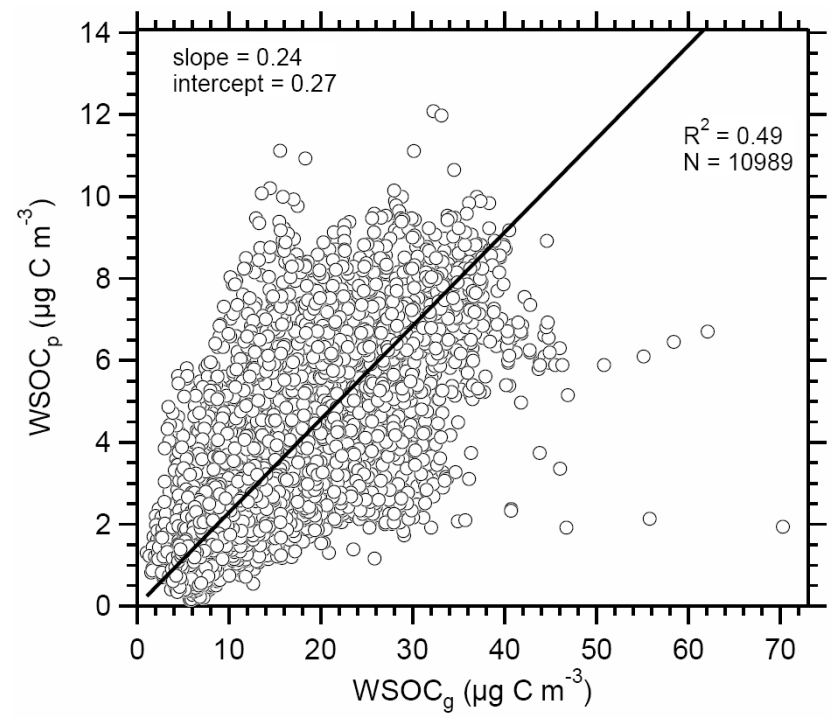

Fig. 1. Scatter plot of $\mathrm{WSOC}_{p}$ versus $\mathrm{WSOC}_{g}$ for the entire summer data set and Deming linear regression results (note, using standard linear regression analysis, the slope is 0.23 if the fitted line is forced through 0 ).

between the observed data and fitted line in both the $\mathrm{x}$ and $\mathrm{y}$ directions and is more appropriate than regular linear regression for this type of data (Cornbleet and Gochman, 1979)). The range of $\mathrm{WSOC}_{g}$ concentrations observed for the entire summer was 1.1-73.1 $\mu \mathrm{g} \mathrm{C} \mathrm{m}^{-3}$, and the mean $\mathrm{WSOC}_{g}$ concentration was $13.7 \mu \mathrm{g} \mathrm{Cm}^{-3}$. Overall, $\mathrm{WSOC}_{p}$ and $\mathrm{WSOC}_{g}$ were correlated during the summer, though there was a large amount of scatter in the data (Fig. 1). A Deming linear regression gives a slope of 0.24 and an intercept of $0.27 \mu \mathrm{g} \mathrm{C} \mathrm{m}^{-3}$, as shown in the $\mathrm{WSOC}_{p}$ vs. $\mathrm{WSOC}_{g}$ plot of Fig. 1 (if forced through 0 , standard linear regression gives a slope of 0.23).

Since $\mathrm{WSOC}_{p}$ and $\mathrm{WSOC}_{g}$ have oxygenated functional groups, it is expected that both are mostly secondary. In Atlanta, particle and gas-phase WSOC originate mainly from biogenic VOC oxidation, since they dominate the VOC emissions budget (Environmental Protection Agency, National Emissions Inventory; Guenther et al., 1994). The correlation between $\mathrm{WSOC}_{p}$ and $\mathrm{WSOC}_{g}$ (Fig. 1) supports a common source (biogenic VOCs). The large amount of scatter in the data, however, may indicate differences that include their formation mechanisms and atmospheric lifetimes.

The average diurnal trends of $\mathrm{WSOC}_{p}$ and $\mathrm{WSOC}_{g}$ are shown in Fig. 2. $\mathrm{WSOC}_{p}$ reached an average daily maximum of $3.8 \mu \mathrm{g} \mathrm{C} \mathrm{m}^{-3}$ at 14:00 Local Time (Eastern Daylight Time). On average, $\mathrm{WSOC}_{p}$ steadily increased in concentration from a morning minimum of $3.1 \mu \mathrm{g} \mathrm{C} \mathrm{m}^{-3}$ at 06:00 Local Time to a daily maximum of $3.8 \mu \mathrm{g} \mathrm{C} \mathrm{m}^{-3}$ at 14:00. Following the afternoon concentration maximum, the average $\mathrm{WSOC}_{p}$ concentration decreased until it reached a level of $3.2 \mu \mathrm{g} \mathrm{C} \mathrm{m}^{-3}$ at 20:00. During the evening and 


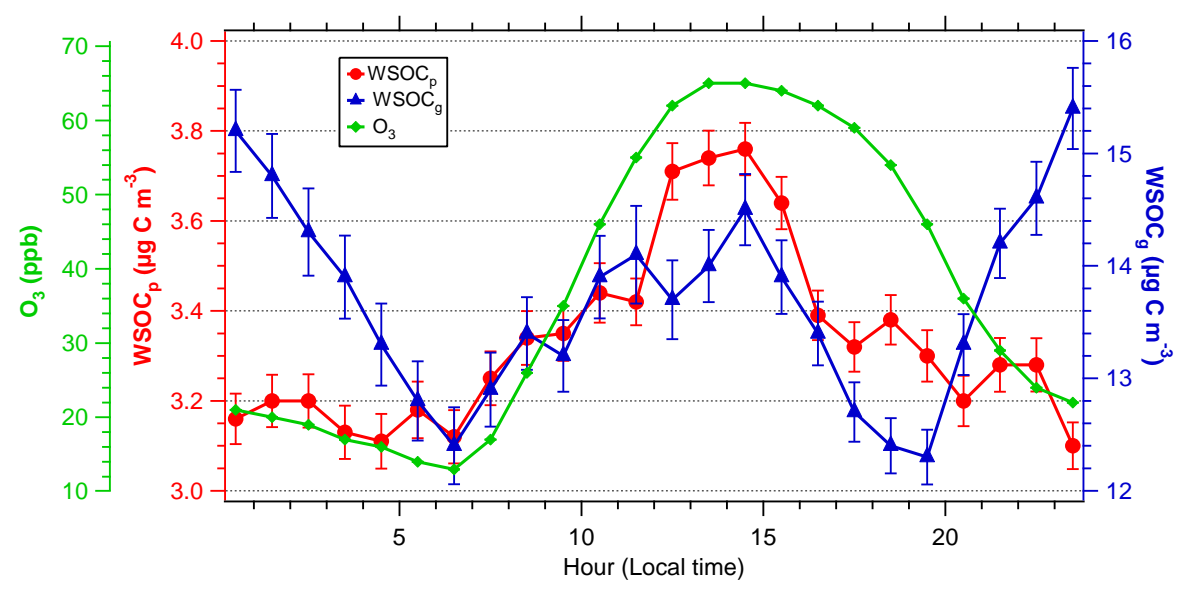

Fig. 2. Average diurnal profiles for $\mathrm{O}_{3}, \mathrm{WSOC}_{p}$, and $\mathrm{WSOC}_{g}$. The vertical bars on each data point represent the standard error (standard deviation $/ \sqrt{ } \mathrm{N})$.

night (between 20:00 and 06:00 the next morning) the mean $\mathrm{WSOC}_{p}$ concentration was relatively constant, ranging between $3.1-3.3 \mu \mathrm{g} \mathrm{C} \mathrm{m}^{-3}$. Between the hours of 06:00 and 20:00, diurnal profiles of $\mathrm{WSOC}_{p}$ and $\mathrm{WSOC}_{g}$ were highly similar. The average $\mathrm{WSOC}_{g}$ peak concentration also occurred at 14:00 $\left(14.5 \mu \mathrm{g} \mathrm{C} \mathrm{m}^{-3}\right)$ in between minima at 06:00 $\left(12.4 \mu \mathrm{g} \mathrm{C} \mathrm{m}^{-3}\right)$ and 19:00 $\left(12.3 \mu \mathrm{g} \mathrm{C} \mathrm{m}^{-3}\right)$. The mid-day increases in $\mathrm{WSOC}_{p}$ and $\mathrm{WSOC}_{g}$ concentrations suggest that photochemical formation was one of the primary sources for secondary organic gases and particles in Atlanta, but the relatively modest enhancement $(\sim 20 \%)$ over pre-sunrise concentrations indicates a substantial regional WSOC background and a relatively long lifetime of both classes of material. This is consistent with the findings of Weber et al. (2007), who showed the highly regional nature of $\mathrm{WSOC}_{p}$ in and around Atlanta.

Figure 2 also indicates that substantial $\mathrm{WSOC}_{g}$ formation occurred through nighttime processes that did not lead to significant enhancements in the $\mathrm{WSOC}_{p}$ concentration. Unlike $\mathrm{WSOC}_{p}$, the $\mathrm{WSOC}_{g}$ concentration increased at night and had another maximum $\left(15.4 \mu \mathrm{g} \mathrm{C} \mathrm{m}^{-3}\right)$ at 23:00. This nighttime $\mathrm{WSOC}_{g}$ increase was approximately equal to the daytime (i.e., photochemical) concentration increase, indicating the importance of this nighttime $\mathrm{WSOC}_{g}$ source. This difference led to a lower $\mathrm{WSOC}_{p} / \mathrm{WSOC}_{g}$ slope at night $(0.22)$ than during the day $(0.26)$.

Ambient studies suggest that nighttime sources for biogenic VOCs may be relatively common. Significant dark emissions of monoterpens from pine species have been observed (e.g., Simon et al., 1994; Hakola et al., 2000; Janson et al., 2001) and, though isoprene emissions are driven by light and temperature (Tingey et al., 1979), Warneke et al. (2004) observed a buildup of isoprene concentrations in the lateafternoon/early evening as the $\mathrm{OH}$ concentration decreased. Dark biogenic VOC oxidation is known to occur through re- actions with both $\mathrm{O}_{3}$ and the nitrate radical $\left(\mathrm{NO}_{3}\right)$ (Griffin et al., 1999), though our observations imply that $\mathrm{NO}_{3}$ was the dominant oxidant initiating nighttime $\mathrm{WSOC}_{g}$ formation for this study. From 19:00 to midnight, when the $\mathrm{WSOC}_{g}$ nighttime concentration peaked, the average $\mathrm{O}_{3}$ concentration decreased sharply from $46 \mathrm{ppb}$ to $22 \mathrm{ppb}$ (Fig. 2). Also, the average nighttime trend of $\mathrm{WSOC}_{g}$ closely resembled the average diurnal profile of $\mathrm{NO}_{3}$ observed in other studies (Stark et al., 2007). It is noteworthy that a reaction mechanism, presumably between biogenic VOCs and $\mathrm{NO}_{3}$, would produce significant $\mathrm{WSOC}_{g}$ and yet little $\mathrm{WSOC}_{p}$ relative to daytime production. Yields of $\alpha$-pinene or isoprene reaction with $\mathrm{NO}_{3}$ are consistent with our observations of minimal increases in nighttime $\mathrm{WSOC}_{p}$. Hallquist et al. (1999) observed SOA yields from the reaction of $\mathrm{NO}_{3}$ with $\alpha$ - pinene of less than $1 \%$. If the $3.1 \mu \mathrm{g} \mathrm{C} \mathrm{m}^{-3}$ increase in $\mathrm{WSOC}_{g}$ (between 19:00-midnight) was due largely to an $\alpha$-pinene $-\mathrm{NO}_{3}$ reaction that had an aerosol yield of $1 \%$ or less, then a correlated nighttime increase in $\mathrm{WSOC}_{p}$ would not be expected since the signal would not be detected above random variability. Since isoprene emissions are high in the Southeast (Guenther et al., 1994), and since it may build up in the evening due to afternoon emissions combined with diminishing $\mathrm{OH}$ (Warneke et al., 2004), the nighttime $\mathrm{WSOC}_{g}$ increase may also have been due to reactions of isoprene with $\mathrm{NO}_{3}$. Ng et al. (2008) found SOA yields from the isoprene$\mathrm{NO}_{3}$ reaction that ranged from $4.3-23.8 \%$ in terms of organic mass, or roughly 2 to $12 \%$ on a carbon mass basis (Brown et al., 2009). The isoprene SOA yields were a strong function of the amount of isoprene reacted and total organic loading, indicating that yields in the ambient atmosphere are likely to be on the low end of the range reported by $\mathrm{Ng}$ et al. (2008) since the chamber concentrations were, in general, higher than ambient. Thus, like $\alpha$-pinene $-\mathrm{NO}_{3}$, yields of only a few percent for isoprene $-\mathrm{NO}_{3}$ reactions would not produce 


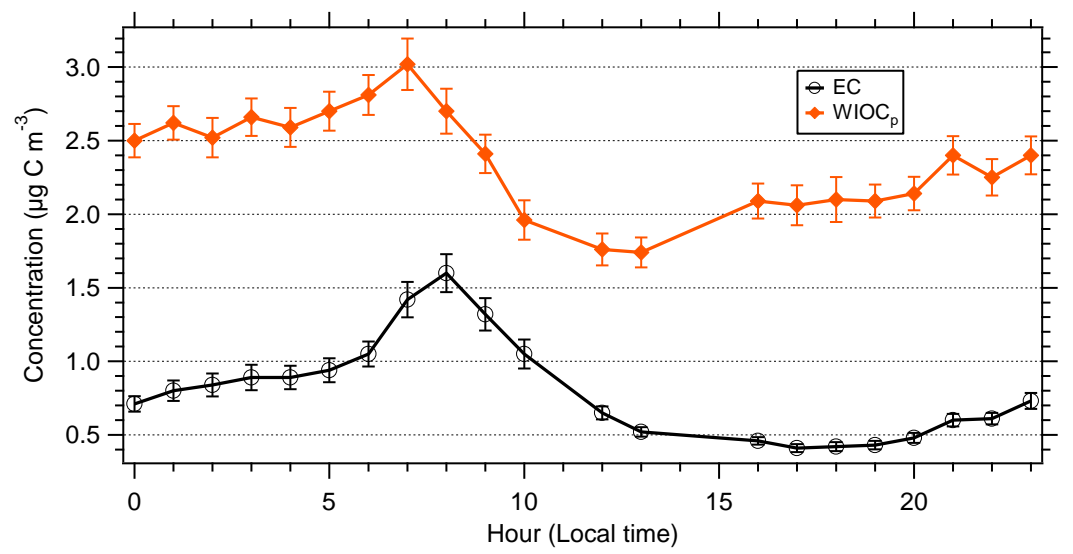

Fig. 3. Average diurnal profiles of EC and Water-Insoluble Organic Carbon (WIOC $p$ ). WIOC $p$ was not measured directly, but was calculated as OC-WSOC $_{p}$. The vertical bars on each data point represent the standard error (standard deviation/ $\sqrt{ } \mathrm{N}$ ).

an appreciable amount of $\mathrm{WSOC}_{p}$ at the observed nighttime $\mathrm{WSOC}_{g}$ concentrations. Recent field observations suggest that background $\mathrm{WSOC}_{p}$ concentrations may limit our ability to detect SOA enhancements from nighttime isoprene oxidation (Brown et al., 2009). For relatively high $\mathrm{WSOC}_{p}$ background conditions, nighttime isoprene oxidation did not appear to contribute significantly to $\mathrm{WSOC}_{p}$ concentrations. This was opposed to observations with a relatively low background $\mathrm{WSOC}_{p}$ concentration where nighttime isoprene oxidation did produce a detectable $\mathrm{WSOC}_{p}$ concentration increase. In each case, the amount of isoprene oxidized was comparable. Although the relatively high and persistent concentrations of $\mathrm{WSOC}_{p}$ in Atlanta may be a factor, the data suggest that if nighttime isoprene oxidation occurred, it may have been a significant source for nighttime $\mathrm{WSOC}_{g}$, but it was not a significant source of $\mathrm{WSOC}_{p}$ compared to daytime production. Finally, smog chamber studies indicate that SOA yields from $\mathrm{NO}_{3}$ reaction with biogenic VOCs other than isoprene and $\alpha$-pinene (i.e., $\beta$-pinene, $\Delta^{3}$-carene, or sabinene, Griffin et al., 1999) are likely to be higher. For these compounds, the production of a significant mass of oxidized gasphase species (e.g., $\mathrm{WSOC}_{g}$ ) would be accompanied by a significant increase in SOA (e.g., $\mathrm{WSOC}_{p}$ ) as well. Because this was not observed in our ambient data, the yields are either lower, or the concentrations of these VOCs too low to significantly contribute to $\mathrm{WSOC}_{g}$. Overall, the reaction of $\mathrm{NO}_{3}$ with some combination of $\alpha$-pinene and isoprene was likely responsible for the nighttime increase in $\mathrm{WSOC}_{g}$ concentration.

\subsection{WSOC partitioning}

The fraction of total WSOC in the particle phase, $F_{p}$, is used to investigate partitioning, by,

$$
F_{p}=\frac{\mathrm{WSOC}_{p}}{\mathrm{WSOC}_{p}+\mathrm{WSOC}_{g}}
$$

$F_{p}$ is related to the $\mathrm{WSOC}_{p} / \mathrm{WSOC}_{g}$ concentration ratio:

$f_{p}=\frac{\mathrm{WSOC}_{p}}{\mathrm{WSOC}_{g}}=\frac{F_{p}}{1-F_{p}}$

There is evidence that, in the absence of significant biomass burning influence, the compounds that make up $\mathrm{WSOC}_{p}$ are largely secondary (Sullivan et al., 2006; Weber et al., 2007), although $\mathrm{WSOC}_{p}$ may not be a completely comprehensive measurement of SOA in certain locations. For example, SOA estimated by the EC tracer method in Tokyo was highly correlated with $\mathrm{WSOC}_{p}\left(R^{2}=0.70-0.79\right)$ and observed $\mathrm{WSOC}_{p} / \mathrm{SOA}$ slopes were $0.67-0.75$ (Miyazaki et al., 2006). The same study also found $90 \%$ or more of primary organic aerosol to be insoluble in water. A study by Favez et al. (2008) observed prominent formation of water-insoluble SOA in Cairo, a highly arid urban center. In Atlanta however, $\mathrm{WSOC}_{p}$ is accounting for most, if not all, of the SOA. This can be seen from Fig. 3, where strong similarities between the mean diurnal profiles of water-insoluble organic carbon $\left(\mathrm{WIOC}_{p}=\mathrm{OC}-\mathrm{WSOC}_{p}\right)$ and elemental carbon (EC) are evident, indicating that it is mostly primary. Clear differences between the diurnal trends of $\mathrm{WIOC}_{p}$ and $\mathrm{WSOC}_{p}$ indicate very different sources between the two. Many studies have established that organic compounds constitute one of the largest fractions of $\mathrm{PM}_{2.5}$ in Atlanta (e.g., Weber et al., 2003; Chu et al., 2004), thus at $\sim 70 \%$ (gC/gC) of the summertime OC, processes contributing to $\mathrm{WSOC}_{p}$ (i.e., SOA) have a large impact on the region's air quality. Additionally, because of the high contribution of $\mathrm{WSOC}_{p}$ to the total SOA, these results describe the partitioning behavior of a significant fraction of SOA in an ambient atmosphere. Various factors that may influence $F_{p}$ are investigated in the following sections. 


\subsubsection{The $F_{p}$-temperature relationship}

According to equilibrium gas/particle partitioning theory, temperature $(T)$ imparts a strong effect on the gas/particle partitioning of organic compounds (Pankow and Bidleman, 1991). From Pankow (1994), an expression for the partitioning constant, $K_{p}$, is

$K_{p}=\frac{C_{p} / M_{o}}{C_{g}}=\frac{760 R T f_{o m}}{10^{6} M W_{o m} \zeta p_{i}^{\circ}}$

where $K_{p}$ has units of $\mathrm{m}^{3} \mu \mathrm{g}^{-1}, C_{p}$ is the compound's particle-phase concentration, $M_{o}$ is the mass concentration of the absorbing organic phase (including water), and $C_{g}$ is the compound's gas-phase concentration. $K_{p}$ can also be predicted from the properties of the partitioning species, where $R$ is the ideal gas constant, $T$ is temperature, $f_{o m}$ is the absorbing fraction of total particulate mass, $M W_{o m}$ is the average molecular weight of the absorbing organic (and aqueous) phase, $\zeta$ is the particle-phase activity coefficient, and $p_{i}^{\circ}$ is the saturation vapor pressure. The vapor pressures of organic compounds approximately double for every $10 \mathrm{~K}$ temperature increase (Seinfeld et al., 2001). Thus, the temperature effect on partitioning in the ambient atmosphere will be dominated by the temperature effect on individual compound saturation vapor pressures, with higher temperature favoring the gas-phase and lower temperature favoring the particle phase. A strong temperature effect on SOA formation was observed in chamber studies using anthropogenic (toluene, $\mathrm{m}$-xylene, 1,2,4-trimethylbenzene) and biogenic ( $\alpha$-pinene) VOCs (Takekawa et al., 2003).

For our ambient measurements, the box plot of Fig. 4 shows that there was no well-defined relationship between $F_{p}$ and temperature (for median $F_{p}$ vs. $T, R^{2}=0.02$ ), (also no relationship between $f_{p}$ and temperature). The ambient temperature range was large enough (greater than $20^{\circ} \mathrm{C}$ ) that any effect of temperature on WSOC partitioning should be present. It is likely, however, that a discernable temperature effect on partitioning was obscured by other temperaturedependent processes affecting WSOC and its precursor emissions.

Overall, concentrations of both $\mathrm{WSOC}_{p}\left(R^{2}=0.22\right)$ and $\mathrm{WSOC}_{g}\left(R^{2}=0.24\right)$ were weakly correlated with temperature, however median concentrations of $\mathrm{WSOC}_{p}\left(R^{2}=0.91\right)$ and WSOC $_{g}\left(R^{2}=0.97\right)$ were highly correlated with temperature (Fig. 5a, b). This indicates that multiple factors influenced WSOC concentrations, but the central tendency over the entire summer was for higher WSOC concentrations to be associated with higher temperatures. The high correlation with median concentrations accompanied with a large amount of scatter in the overall data (evident from the spread in 10th, 25th, 75th, and 90th percentile values in Fig. 5) implicates temperature as one of multiple factors that affected WSOC concentrations. The emissions of biogenic precursors to WSOC (Tingey et al., 1980) and the photochemical formation of WSOC (Tsigaridis et al., 2005) are both positively

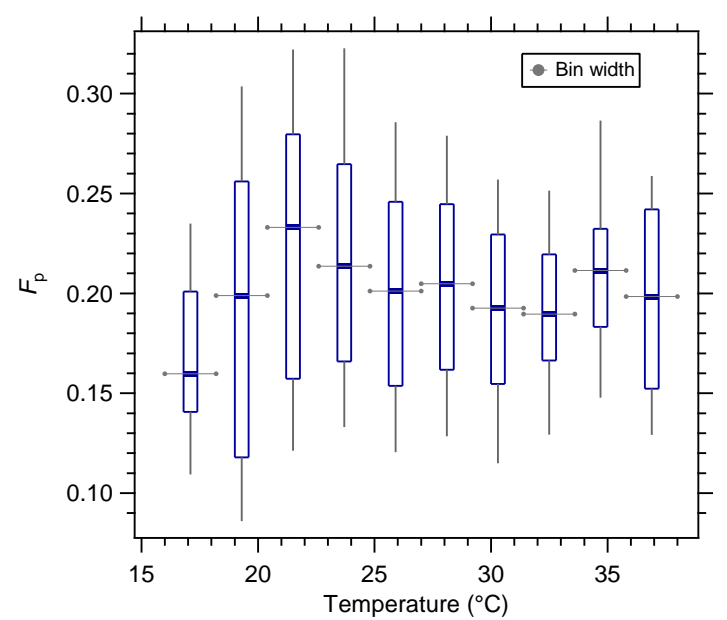

Fig. 4. Box plot of particulate WSOC fraction, $F_{p}$, versus Temperature. The box plot was generated by segregating the data into ten equally-spaced temperature bins (average $N$ per bin $=1040$ ), and median values (thick horizontal bar), 25th and 75th percentiles (lower and upper box bounds, respectively), and 10th and 90th percentiles (lower and upper whiskers, respectively) for each bin are plotted.

related to temperature, and likely explain these trends. This suggests that the positive effects of temperature on biogenic emissions and reactivity may dominate over the negative effect of volatility on $\mathrm{WSOC}_{p}$, demonstrated by the increase in both $\mathrm{WSOC}_{g}$ and $\mathrm{WSOC}_{p}$ with temperature.

It is possible that a temperature effect on WSOC gas/particle partitioning did exist, but was not visible due to the relationships $\mathrm{WSOC}_{p}$ and $\mathrm{WSOC}_{g}$ exhibited with temperature (Fig. 5a, b). The slopes of the median WSOC $_{p}-T$ and the median $\mathrm{WSOC}_{g}-T$ correlation lines were $0.199 \mu \mathrm{g} \mathrm{C} / \mathrm{m}^{3} /{ }^{\circ} \mathrm{C}$ and $0.821 \mu \mathrm{g} \mathrm{C} / \mathrm{m}^{3} /{ }^{\circ} \mathrm{C}$, respectively. If background concentrations of $\mathrm{WSOC}_{p}$ and $\mathrm{WSOC}_{g}$ are both assumed zero, then, using the median relationships, a nominal temperature change would produce a constant $F_{p}$ value of 0.195 , which compares closely with the mean $F_{p}$ for the entire study (0.203). This supports the view that a temperaturepartitioning effect was obscured and highlights the dynamic nature of the ambient system in which the measurements were made. Specifically, an increase in temperature led to additional inputs of WSOC (particle and gas) into the system that made the determination of a specific temperature effect on partitioning ambiguous. This difficulty with ambient sampling underscores the need to pair ambient measurements with controlled laboratory experiments that can isolate experimental variables.

\subsubsection{The $F_{p}-\mathrm{RH}$ and liquid water relationship}

Hennigan et al. (2008a) observed, at RH levels $>70 \%$, a strong increase in $F_{p}$ with RH that was likely due to liquid water uptake by fine $\left(\mathrm{PM}_{2.5}\right)$ particles. This was evident from 
the similarities between the $F_{p}$-RH curve and the two other independent predictions of liquid water uptake as a function of RH (Fig. 6). The RH effect on gas/particle partitioning led to increases in SOA mass $\left(0.3-0.9 \mu \mathrm{g} \mathrm{C} \mathrm{m}^{-3}\right)$ that were significant in the context of ambient concentrations. Figure 6 indicates a positive linear relationship between $F_{p}$ and predicted liquid water concentration (linear regression $R^{2}$ between median $F_{p}$ and liquid water for $\mathrm{RH}>45 \%$ is 0.997 , $n=5$ ). The relationship between $F_{p}$ and RH had no apparent diurnal variability, as it was nearly constant across daytime and nighttime conditions (Hennigan et al., 2008a). This explains why, though this may be a significant source of $\mathrm{WSOC}_{p}$ in Atlanta, the only diurnal signature evident for $\mathrm{WSOC}_{p}$ was the obvious photochemical source. Although these results point to a Henry's Law-type partitioning process (by Henry's Law the ratio of particle to gas concentration is directly proportional to liquid water concentration), we have noted that Henry's Law partitioning alone cannot account for the significant increase in $F_{p}$ observed at elevated RH levels (Hennigan et al., 2008a). Additionally, application of Henry's Law assumes dissolution into an ideal solution, while ambient particles are non-ideal. The liquid water increase, even in a polluted atmosphere under high RH ( $>90 \%$ ), is not enough to simply dissolve soluble semivolatile gases (e.g., acetic acid or formic acid, etc.) and account for the SOA increase (Hennigan et al., 2008a). Using $10 \mu \mathrm{g} \mathrm{m}^{-3}$ liquid water concentration and an $F_{p}$ value of 0.3 (approximately equal to the observed $F_{p}$ above $90 \% \mathrm{RH}$ ), we calculate an effective Henry's Law constant for the total WSOC of $\sim 2 \times 10^{9} \mathrm{M} \mathrm{atm}^{-1}$. This value agrees well with the experimentally-derived value of Volkamer et al. (2009), and suggests that condensed phase reactions are playing an important role in $\mathrm{WSOC}_{p}$ formation in Atlanta.

Seinfeld et al. (2001) predict a substantial influence of liquid water on SOA formation due to the effect of the uptake of water on two terms in Eq. (3), $M W_{o m}$ and $\zeta$. Though the effects of $M W_{\text {om }}$ and $\zeta$ due to water uptake may be in competition, depending on the hydrophilic nature of the partitioning SVOCs, Seinfeld et al. (2001) predicted overall higher $K_{p}$ values (more partitioning to the particle phase) at higher liquid water levels. Pun and Seigneur (2007) also predict an enhancing effect of aerosol water on SOA formation due to the greater absorptive capacity of added water (the role in $M_{o}$, Eq. 3), its decreasing effect on the $M W_{o m}$ term (thus increasing $K_{p}$ ), and acid-catalyzed oligomer formation in the aqueous phase from glyoxal. Chang and Pankow (2008) propose an SOA model that incorporates the effects of water on $M W_{o m}$ and $\zeta$, as shown by Seinfeld et al. (2001), while also including phase separation considerations.

At present, understanding the effect of humidity on SOA formation is incomplete. It is known that water vapor affects the oxidation pathway of terpene ozonolysis, and thus, SOA formation by this mechanism (e.g., Bonn and Moortgat, 2002; Jonsson et al., 2006; Stenby et al., 2007). Bonn et al. (2002) showed that, strictly through an effect on gas-phase
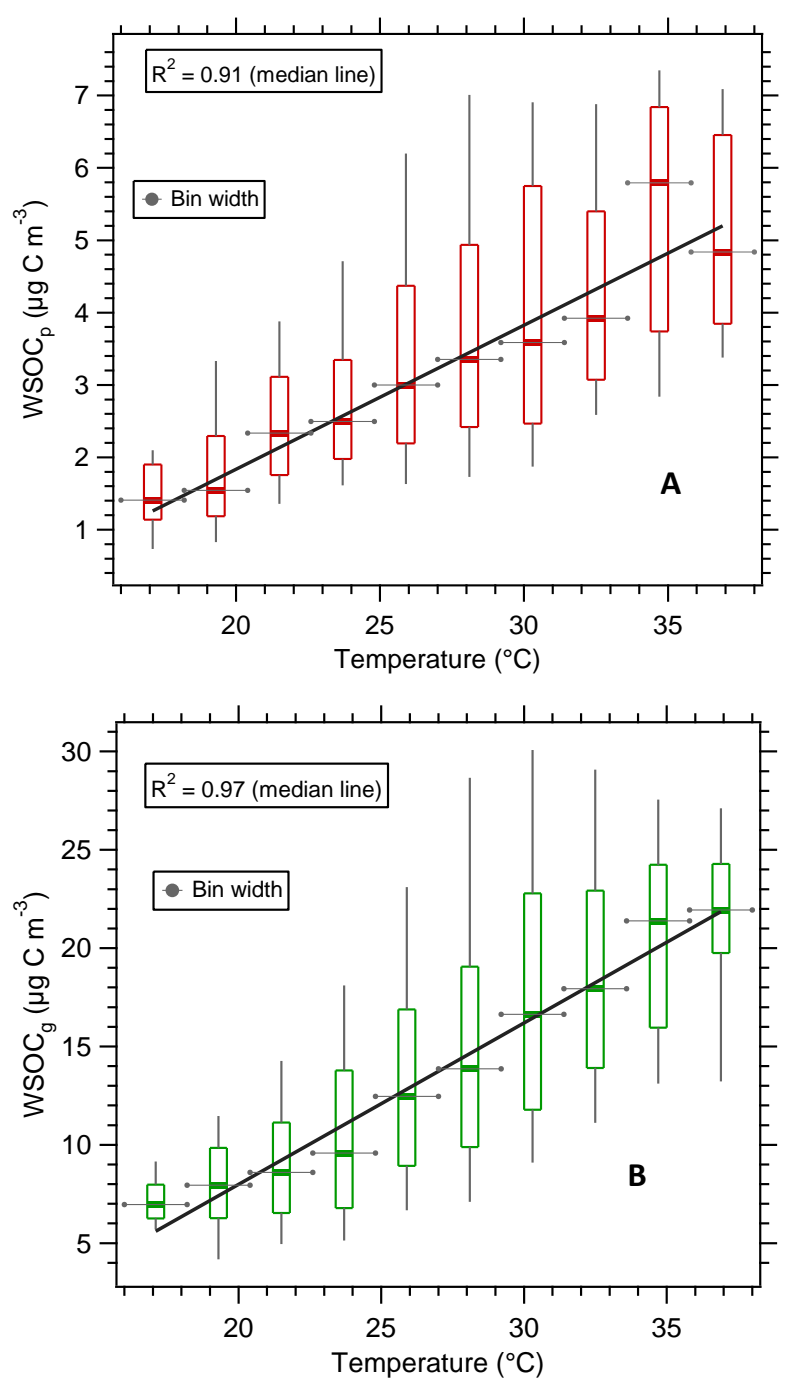

Fig. 5. Box plots of $\mathrm{WSOC}_{p}$ (a) and $\mathrm{WSOC}_{g}$ (b) versus Temperature. The plots show median values (thick horizontal bar), 25th and 75th percentiles (lower and upper box bounds, respectively), and 10th and 90th percentiles (lower and upper whiskers, respectively) for each bin. For the $\mathrm{WSOC}_{p}-T$ plot (a), the average $N$ per bin $=1803$, and for the $\mathrm{WSOC}_{g}-T$ plot, the average $N$ per bin $=1165$.

chemistry, water vapor is likely to influence SOA formation only through oxidation processes initiated by $\mathrm{O}_{3}$, and not $\mathrm{OH}$ or $\mathrm{NO}_{3}$. Experimentally, the effect of liquid water on SOA formation appears to be variable. Smog chamber studies by Cocker et al. (2001a, b) found no enhancement in SOA formation from $\alpha$-pinene, m-xylene, or 1,3,5-trimethylbenzene due to liquid water. Edney et al. (2000) also found no water effect on SOA formation in smog chamber studies with toluene as the precursor VOC. In contrast, Volkamer et al. (2009) observed a positive linear dependence between acetylene $\left(\mathrm{C}_{2} \mathrm{H}_{2}\right)$ SOA yields and the liquid water content of particles in chamber experiments. This was attributed to the 
gas phase hydroxyl radical $(\mathrm{OH})$ oxidation of $\mathrm{C}_{2} \mathrm{H}_{2}$ to produce glyoxal and its subsequent uptake and reaction in the aqueous phase. The variable effects of liquid water observed between smog chamber studies may be due to differing experimental conditions, or to differences in the water solubilities of the oxidation products from different precursor VOCs. Overall, our ambient results showed a strong effect of RH on $F_{p}$, and so are in better agreement with the smog chamber results of Volkamer et al. (2009) and less-so with the traditional partitioning theory involving $K_{p}$.

\subsubsection{The $F_{p}-\mathrm{NO}_{\mathrm{x}}$ relationship}

In addition to relative humidity, the data demonstrate that $\mathrm{NO}_{\mathrm{x}}$ levels impacted $F_{p}$ as well. A box plot of $F_{p}$ versus $\mathrm{RH}$ was constructed after sorting the data according to $\mathrm{NO}_{\mathrm{x}}$ mixing ratios, and mean values are plotted for the high $\mathrm{NO}_{\mathrm{x}}$ and low $\mathrm{NO}_{\mathrm{x}}$ data (Fig. 7a). The mean $\mathrm{NO}_{\mathrm{x}}$ mixing ratio for the high $\mathrm{NO}_{\mathrm{x}}$ data was $33 \pm 23 \mathrm{ppb}($ mean $\pm 1 \sigma)$ while that for the low $\mathrm{NO}_{\mathrm{x}}$ data was $6 \pm 2 \mathrm{ppb}$ (mean $\pm 1 \sigma$ ). Below $80 \% \mathrm{RH}$, low $\mathrm{NO}_{\mathrm{x}}$ conditions were associated with higher values of $F_{p}$ (mean=0.208), while high $\mathrm{NO}_{\mathrm{x}}$ conditions were associated with lower values of $F_{p}$ (mean $\left.=0.180\right)$. Overall, the mean $F_{p}$ difference $(0.028)$ below $80 \% \mathrm{RH}$ was statistically significant at the $99.9 \%$ confidence interval ( $t=7.793$ from student's t-test, $d f=1046)$. Multiplying this $\Delta F_{p}$ by the mean total WSOC concentration below $80 \% \mathrm{RH}\left(18.58 \mu \mathrm{g} \mathrm{C} \mathrm{m}^{-3}\right)$ yields a $\mathrm{WSOC}_{p}$ enhancement from this difference of $0.52 \mu \mathrm{g} \mathrm{C} \mathrm{m}^{-3}$. The difference in $F_{p}$ values between high $\mathrm{NO}_{\mathrm{x}}$ and low $\mathrm{NO}_{\mathrm{x}}$ regimes (0.028) may appear small, despite its statistical significance. However, the difference is non-negligible given that the mean $\mathrm{WSOC}_{p}$ concentration for the entire summer was $3.3 \mu \mathrm{g} \mathrm{C} \mathrm{m}^{-3}$.

The difference in WSOC partitioning with $\mathrm{NO}_{\mathrm{x}}$ levels could explain the $F_{p}$ differences observed between the nighttime and the daytime, where generally more WSOC was partitioned in the particle phase during the day than at night (Hennigan et al., 2008a). Though it is possible that the day/night differences in $F_{p}$ were not driven by changes in $\mathrm{NO}_{\mathrm{x}}$ levels, the evidence for a $\mathrm{NO}_{\mathrm{x}}$ effect is compelling. Median $F_{p}$ values had a strong negative linear correlation $(R=-0.97)$ to the $\mathrm{NO}_{\mathrm{x}}$ mixing ratio (Fig. 7b). (Note, correlation remains strong $(R=-0.84)$ even with the highest $\mathrm{NO}_{\mathrm{x}}$ point removed). The data was also subdivided into day/night periods to investigate the role of $\mathrm{NO}_{\mathrm{x}}$ during these times. When only daytime data was considered, the mean $F_{p}$ value corresponding to the top $15 \%$ of $\mathrm{NO}_{\mathrm{x}}$ mixing ratios was statistically lower (at the $99.5 \%$ confidence level) than the mean $F_{p}$ value for the bottom $15 \%$ of $\mathrm{NO}_{\mathrm{x}}$ mixing ratios $(t=3.111$ from student's t-test, $d f=264)$. This was also the case for nighttime only data ( $t=4.676$ from student's t-test, $d f=335$ ) and it supports the existence of a $\mathrm{NO}_{\mathrm{x}}$ effect on $F_{p}$ versus an indirect impact from another effect, such as oxidant $(\mathrm{OH}$, $\mathrm{O}_{3}$ ) concentration.

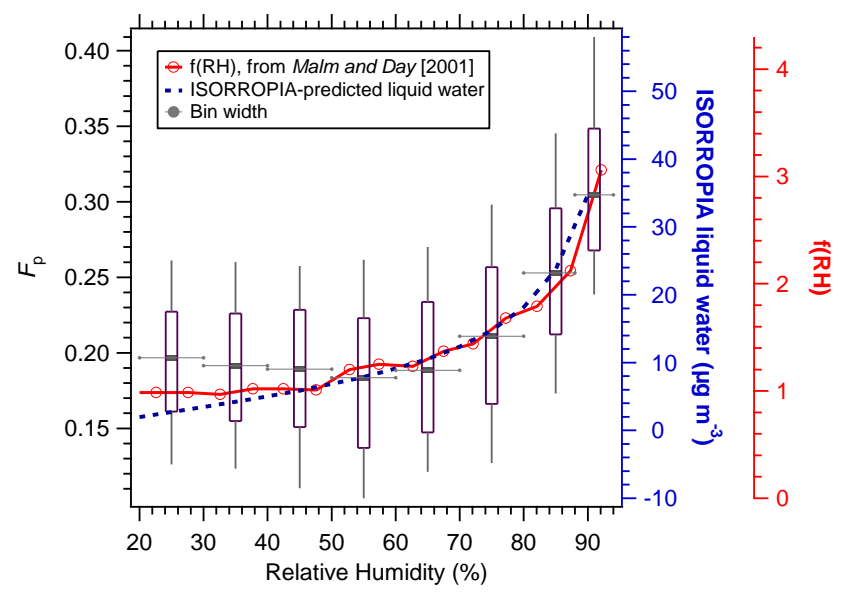

Fig. 6. Relationship between partitioning and liquid water uptake, adapted from Hennigan et al. (2008a). The box and whiskers represent ambient $F_{p}$ data, with median values (thick horizontal bar), 25th and 75th percentiles (lower and upper box bounds, respectively), and 10th and 90th percentiles (lower and upper whiskers, respectively) shown for each bin. ISORROPIA-predicted (Nenes et al., 1998; Fountoukis and Nenes, 2007) liquid water as a function of RH is based on an average inorganic aerosol composition (see Hennigan et al. (2008a) for discussion), and the $\mathrm{f}(\mathrm{RH})$ trace is a measure of the scattering enhancement due to particulate water uptake reported by Malm and Day (2001).

In general, for a given precursor VOC concentration, SOA yields from the reaction of hydrocarbons with ten or fewer carbon atoms are significantly higher at low $\mathrm{NO}_{\mathrm{x}}$ levels compared to high $\mathrm{NO}_{\mathrm{x}}$ levels (Kroll and Seinfeld, 2008). These small hydrocarbons include isoprene (Kroll et al., 2006; Pandis et al., 1991) and monoterpenes (Presto et al., 2005; Ng et al., 2007a), biogenic species with high emission rates in the Southeast (Guenther et al., 1994). Conversely, SOA yields from the reaction of larger hydrocarbons are, in general, highest at high $\mathrm{NO}_{\mathrm{x}}$ levels (Kroll and Seinfeld, 2008). The $\mathrm{NO}_{\mathrm{x}}$ effect on SOA yields arises from its substantial influence on the oxidant initiating SOA formation (i.e., hydroxyl radical, nitrate radical, or ozone) and on the fate of the $\mathrm{RO}_{2}$ and RO radicals (Kroll and Seinfeld, 2008). In general, reaction of smaller VOCs in the presence of higher $\mathrm{NO}_{\mathrm{x}}$ concentrations leads to the formation of higher volatility products (e.g., fragmentation and formation of short aldehydes) compared to smaller VOC reactions in low $\mathrm{NO}_{\mathrm{x}}$ conditions that produce lower volatility products (e.g., hydroperoxides and acids from reaction of $\mathrm{RO}_{2}+\mathrm{HO}_{2}$ ). As isoprene and monoterpenes are expected to be the major SOA precursors in the southeastern US, the observed relationship between $F_{p}$ and $\mathrm{NO}_{\mathrm{x}}$ is qualitatively consistent with the smog chamber studies which observed a similar phenomenon. It is noted that the absolute $\mathrm{NO}_{\mathrm{x}}$ concentration may not be a critical parameter in VOC oxidation; rather, it is likely the VOC: $\mathrm{NO}_{\mathrm{x}}$ ratio in the air mass during the period of SOA formation which 
impacts the oxidation product distribution (Kroll and Seinfeld, 2008). For this study, parent VOCs were not measured, and thus an analysis of $F_{p}$ as a function of the VOC: $\mathrm{NO}_{\mathrm{x}}$ ratio is not possible. This may partly explain the large spread observed in Fig. 7b, as the parent VOC concentrations were likely highly variable for a given $\mathrm{NO}_{\mathrm{x}}$ concentration.

A limitation with the non-chemically specific approach used here is that $F_{p}$ can depend on both the oxidation process leading to SVOCs and partitioning, similar to the process described by the Yield (Seinfeld and Pandis, 1998). Thus, this data does not provide evidence whether the observed $\mathrm{NO}_{\mathrm{x}}$ effect is due to the types of SVOCs produced under different $\mathrm{NO}_{\mathrm{x}}$ concentrations, or if $\mathrm{NO}_{\mathrm{x}}$ plays a role in partitioning. Given the smog chamber results, the $\mathrm{NO}_{\mathrm{x}}$ effect on the SVOCs product distribution seems the most likely cause for the observed effect on $F_{p}$.

In contrast to $\mathrm{NO}_{\mathrm{x}}$, ozone $\left(\mathrm{O}_{3}\right)$ concentrations did not appear to impact WSOC partitioning at all. The mean $F_{p}$ at $\mathrm{O}_{3}$ concentrations above $70 \mathrm{ppb}(0.211)$ was not statistically different from the mean $F_{p}$ at $\mathrm{O}_{3}$ concentrations below $20 \mathrm{ppb}(0.214)$. This result is in contrast to high aerosol yields from $\mathrm{O}_{3}$ reactions with biogenic VOCs that have been observed in smog chamber studies (e.g., Griffin et al., 1999). It is possible, though, that $\mathrm{O}_{3}$ was prominently involved in VOC oxidation but that $\mathrm{O}_{3}$ was abundant, and VOCs limiting, in $\mathrm{O}_{3}$-VOC reactions and thus little dependence was seen between $F_{p}$ and $\mathrm{O}_{3}$.

\subsubsection{The $\boldsymbol{F}_{p}$-organic aerosol mass relationship}

Equation (3), along with extensive chamber experimental results (Odum et al., 1996; Odum et al., 1997; Hoffmann et al., 1997), suggests that the mass concentration of the absorbing organic phase, $M_{o}$, will also impact equilibrium gas/particle partitioning. The relationship suggests that, at a given temperature, a higher $M_{o}$ will lead to a higher fraction of a partitioning compound in the particle phase due to a greater capacity (i.e., volume) of absorbing medium for the partitioning of SVOCs. Figure 8a shows a box plot of $F_{p}$ as a function of the organic carbon aerosol (OC) mass concentration and suggests that an $F_{p}-M_{o}$ (i.e., $F_{p}-\mathrm{OC}$ ) relationship did not exist across the entire summer. When the data were binned into smaller temperature ranges $\left(<20^{\circ} \mathrm{C}, 20-25^{\circ} \mathrm{C}, 25-30^{\circ} \mathrm{C}\right.$, $>30^{\circ} \mathrm{C}$ ), the same trend was observed as that for the overall analysis; generally no correlation observed between $F_{p}$ and OC. The total OC concentration was used because of (1) the strong dependence of SOA yields and partitioning on the total concentration (by mass) of organic aerosol in smog chamber studies (Odum et al., 1996), and (2) the substantial predictive capability of this method when used for subsequent smog chamber experiments of SOA formation from complex VOC mixtures (Odum et al., 1997). For these reasons, this formulation has been widely applied to air quality models, but these data suggest this may not be appropriate in all environments.
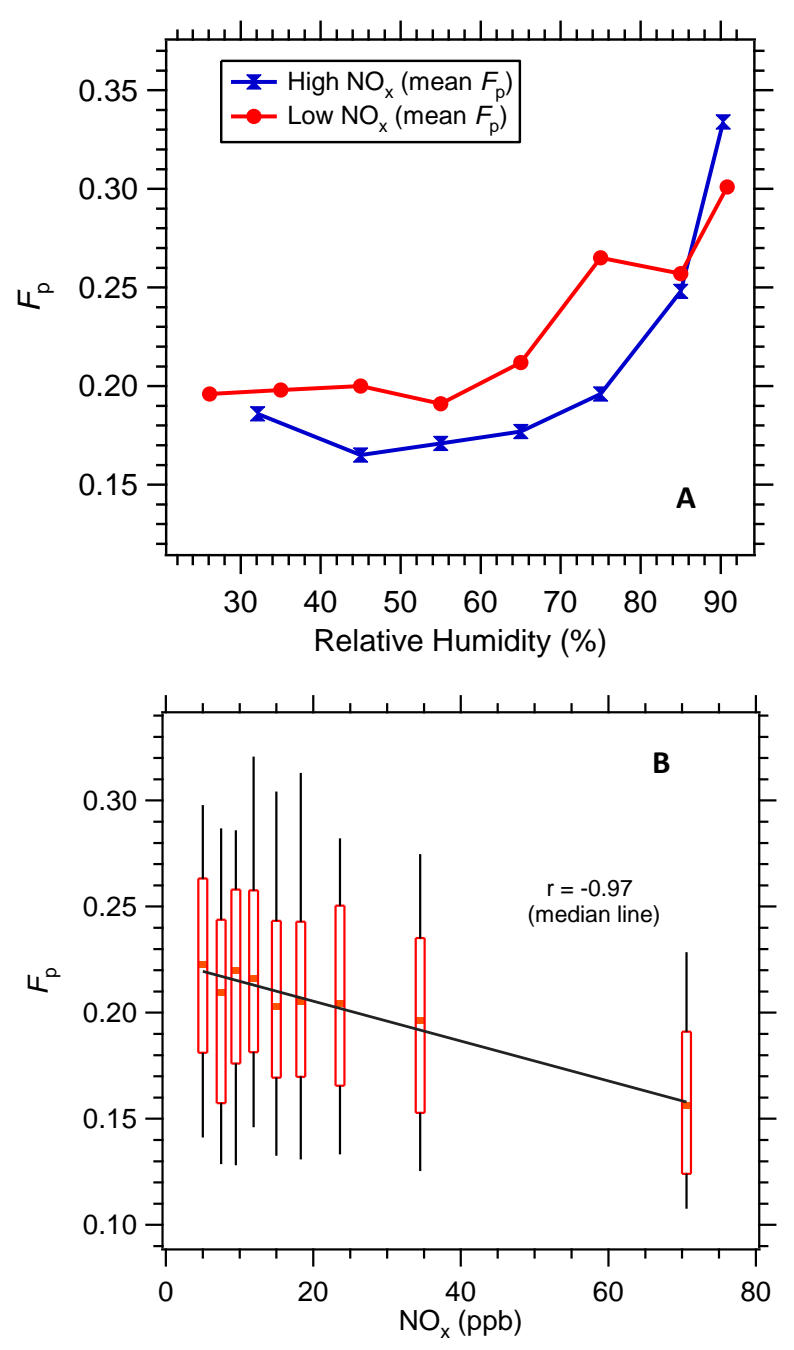

Fig. 7. Relationship between $\mathrm{NO}_{\mathrm{x}}$ and $F_{p}$. Mean $F_{p}$ versus $\mathrm{RH}$ for data sorted by $\mathrm{NO}_{\mathrm{x}}$ mixing ratio (a) (Data represent the highest and lowest $35 \%$ of $\mathrm{NO}_{\mathrm{x}}$ mixing ratios). Particulate WSOC fraction, $F_{p}$, as a function of $\mathrm{NO}_{\mathrm{x}}$ mixing ratio (b). The data were binned according to $\mathrm{NO}_{\mathrm{x}}$ mixing ratios and median (thick horizontal line), 25th and 75th percentiles (lower and upper box), and 10th and 90th percentiles (lower and upper whiskers) are shown for each bin (average $N$ per bin=197).

Following the traditional line of reasoning on SOA formation, because $F_{p}$ describes the partitioning of only watersoluble carbon compounds, $\mathrm{WSOC}_{p}$ may be a more appropriate partitioning medium than $\mathrm{OC}$ due to the higher chemical similarities between $\mathrm{WSOC}_{p}$ and $\mathrm{WSOC}_{g}$ compared to similarities between OC and $\mathrm{WSOC}_{g}$. This greater similarity arises because $\mathrm{WSOC}_{g}$ is oxygenated and thus is predominantly secondary like $\mathrm{WSOC}_{p}$, while $\mathrm{OC}$ is comprised of significant fractions of both secondary and primary components. Alternatively, heterogeneous reactions involving $\mathrm{WSOC}_{p}$ would also be expected to make investigating $F_{p}$ 
relative to $\mathrm{WSOC}_{p}$ a more appropriate parameter than OC.

Using $\mathrm{WSOC}_{p}$ concentrations as the mass of the absorbing organic phase, Fig. $8 \mathrm{~b}$ does suggest a relationship between gas/particle partitioning and existing organic aerosol mass. Higher $\mathrm{WSOC}_{p}$ concentrations were associated with a larger fraction of total WSOC partitioned in the particle phase, however, a dependence was only seen for $\mathrm{WSOC}_{p}$ concentrations below $\sim 4 \mu \mathrm{g} \mathrm{C} \mathrm{m}^{-3}$. That the dependence between $F_{p}$ and $\mathrm{WSOC}_{p}$ appeared to diminish and end at WSOC $_{p}$ above $\sim 4 \mu \mathrm{g} \mathrm{C} \mathrm{m}^{-3}$ may suggest that the "average" $\mathrm{WSOC}_{p}$ sampled in the Atlanta summertime was relatively non-volatile (Seinfeld and Pandis, 1998; Ng et al., 2007b). Lanz et al. (2007) found that approximately $2 / 3$ of the oxygenated aerosol (interpreted as SOA) was non-volatile in Switzerland, where, like Atlanta, most of the SOA is from biogenic precursors in summer.

Note that $F_{p}$ and $\mathrm{WSOC}_{p}$ are related through Eq. (1) and it cannot be ruled out that the behavior of Fig. 8b was an artifact of this $F_{p}-\mathrm{WSOC}_{p}$ relationship. However, since the magnitude of $\mathrm{WSOC}_{g}$ was significantly larger than $\mathrm{WSOC}_{p}$, weakening any $F_{p}-\mathrm{WSOC}_{p}$ direct dependence, there is reason to believe it is real. Additional analyses support this view, and suggest that WSOC partitioning was impacted by the $\mathrm{WSOC}_{p}$ concentration. (A number of tests were undertaken, including applying the Deming regression results of Fig. 1 to predict $F_{p}$, and testing randomly generated lognormal distributions of $\mathrm{WSOC}_{p}$ and $\mathrm{WSOC}_{g}$ based on observed medians and geometric standard deviations. Neither test resulted in an $F_{p}$-WSOC $p$ dependence similar to the observations of Fig. 8b. Furthermore, plotting $F_{p}$ vs. $\mathrm{WSOC}_{p}$ is directly analogous to the plots of SOA Yield vs. $M_{o}$ (e.g., Odum et al., 1996) used to formulate current partitioning theory).

An $F_{p}$ dependence on $\mathrm{WSOC}_{p}$ was also evident when the $\mathrm{WSOC}_{p}$ concentration was incorporated into the $F_{p}$-RH analysis. When the data were sorted according to $\mathrm{WSOC}_{p}$ concentrations (Fig. 9a), there was a substantial difference in mean $F_{p}$ values plotted against $\mathrm{RH}$ for high $\mathrm{WSOC}_{p}$ concentrations (top $35 \%$ of data, mean WSOC $_{p}=5.3 \mu \mathrm{g} \mathrm{C} \mathrm{m}^{-3}$ ) compared with low $\mathrm{WSOC}_{p}$ concentrations (bottom $35 \%$ of data, mean $\mathrm{WSOC}_{p}=1.7 \mu \mathrm{g} \mathrm{C} \mathrm{m}^{-3}$ ). All of the eight points are statistically different at the $99.9 \%$ confidence interval. Note that this high versus low $\mathrm{WSOC}_{p}$ range spans the transition at $\sim 4 \mu \mathrm{g} \mathrm{C} \mathrm{m}^{-3}$ in Fig. $8 \mathrm{~b}$ (i.e., the transition from a $F_{p}-\mathrm{WSOC}_{p}$ dependence to no dependence).

The differences between the $F_{p}-\mathrm{OC}$ and $F_{p}-\mathrm{WSOC}_{p}$ relationships may be due to composition differences between the two systems and may suggest that the chemical nature of the absorbing organic phase is a meaningful parameter to the partitioning process. Specifically, it appears as if the total organic aerosol may not be acting as a partitioning medium for the condensation of water-soluble organic compounds. Rather, only condensed-phase compounds that are water-soluble (and water, itself) participate in the uptake of $\mathrm{WSOC}_{g}$. This is in general agreement with the results of
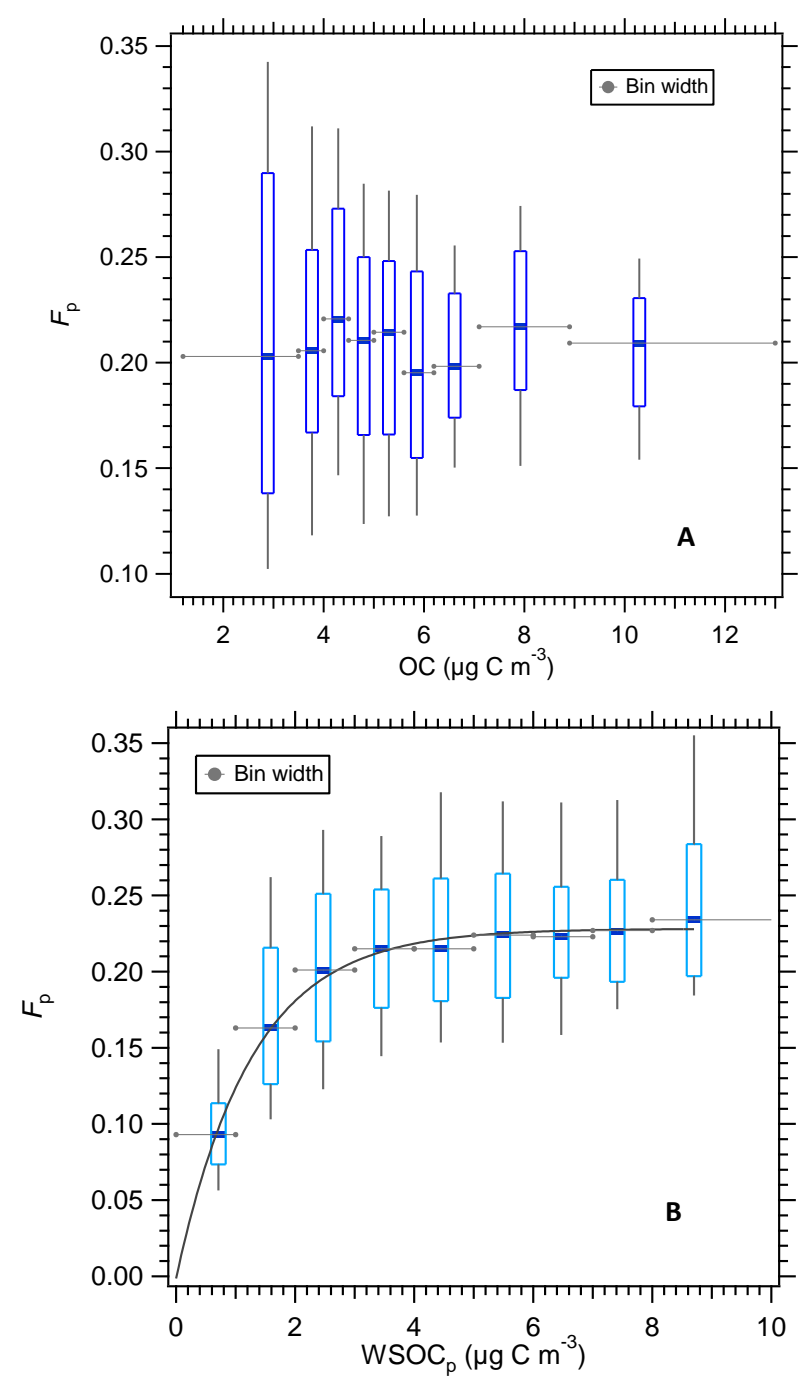

Fig. 8. WSOC partitioning $\left(F_{p}\right)$ as a function of OC concentration (a) and $\mathrm{WSOC}_{p}$ concentration (b). For the box plot of particulate WSOC fraction, $F_{p}$, versus OC (a), which shows median values (thick horizontal bar), 25th and 75th percentiles (lower and upper box bounds, respectively), and 10th and 90th percentiles (lower and upper whiskers, respectively) for each bin, average $N$ per bin $=139$. For the box plot of $F_{p}$ versus $\operatorname{WSOC}_{p}(\mathrm{~b})$, average $N$ per bin $=1220$. The curve is forced through zero based on the definition of $F_{p}$ (Eq. 1).

Song et al. (2007), who observed no relationship between the mass of primary organic aerosol (POA) and the yield of SOA from $\alpha$-pinene, implying that the POA did not actively participate in the SOA formation. Additionally, Volkamer et al. (2009) observed a significant seed composition effect on SOA formation from $\mathrm{C}_{2} \mathrm{H}_{2}$ : yields using ammonium sulfate plus fulvic acid seed particles were a factor of 3-4 higher than yields using only ammonium sulfate seed. The absorbing organic plus aqueous phase has also demonstrated a compositional effect on the partitioning of semi-volatile 
organics in model predictions. Seinfeld et al. (2001) found that the partitioning of hydrophilic compounds to the particle phase was enhanced by particulate water uptake while that for hydrophobic compounds was diminished by water uptake. Bowman and Karamalegos (2002) found a compositional effect on SOA mass concentrations in model simulations based on the effect of the composition-dependent activity coefficient, $\zeta$, on $K_{p}$. It is noteworthy that the differences in $F_{p}$ versus $\mathrm{WSOC}_{p}$ and $\mathrm{OC}$ were present despite an observed high correlation between $\mathrm{WSOC}_{p}$ and OC ( $R^{2}=0.73$, see above), and despite $\mathrm{WSOC}_{p}$ accounting for, on average, $70 \%$ of OC. This implies that approximately $30 \%$ of OC was insoluble in water, and similarities between this water-insoluble organic carbon fraction and the EC diurnal profiles suggest that these insoluble organic compounds

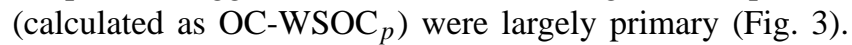
These primary compounds are chemically much different from $\mathrm{WSOC}_{p}$, including significant differences in oxidation, functional groups, and polarity (Saxena and Hildemann, 1996). The primary component of OC, and its different chemical character from that of WSOC, may in part explain the lack of an $F_{p}$ dependence on OC. Though the general trends in data and fit in Fig. $8 \mathrm{~b}$ are somewhat similar to the smog chamber SOA Yield- $M_{o}$ relationship found by Odum et al., (1996), where in that case $M_{o}$ was OC mass formed in the chamber, it is also possible that the $F_{p}-\mathrm{WSOC}_{p}$ relationship resulted from a completely different process than absorptive partitioning. Additionally, the results in Fig. 9a and $\mathrm{b}$ suggest that $\mathrm{RH}$ and $\mathrm{WSOC}_{p}$ impact WSOC partitioning through different means. The high $\mathrm{RH}$ analysis in Fig. 9b only included data with RH levels above $65 \%$ (mean $\mathrm{RH}=78.2 \%$ ) while the low RH analysis only included data with RH levels below $50 \%$ (mean $\mathrm{RH}=38.5 \%$ ). This contrasts how $\mathrm{WSOC}_{p}$ affected partitioning for very wet particles and those with significantly less water.

The results in Fig. 9a and b may indicate that the process is similar on particles containing an abundance of liquid water and particles with a modest liquid water contribution. This has two implications. First, the role that the particle organic component (e.g., $\mathrm{WSOC}_{p}$ ) plays in partitioning is present even when particle $\mathrm{H}_{2} \mathrm{O}$ concentrations likely far exceeded $\mathrm{WSOC}_{p}$ concentrations. This behavior would not be expected if partitioning were described solely by the partitioning coefficient, $K_{p}$. As the liquid water content of particles increases, the importance of water in the partitioning process should increase and the importance of the $\mathrm{WSOC}_{p}$ concentration should diminish. This is due to the significant impact of water on the average molecular weight of the absorbing organic plus aqueous phase, $M W_{o m}$, and on the increase it would bring to the total mass of the absorbing organic plus aqueous phase, $M_{o}$ (Eq. 3). For example, at RH levels above $90 \%$, the liquid water concentration may be an order of magnitude higher than the $\mathrm{WSOC}_{p}$ concentration, and so would dictate any relationship with $M_{o}$. Our ambient results suggest that this did not occur with WSOC par-
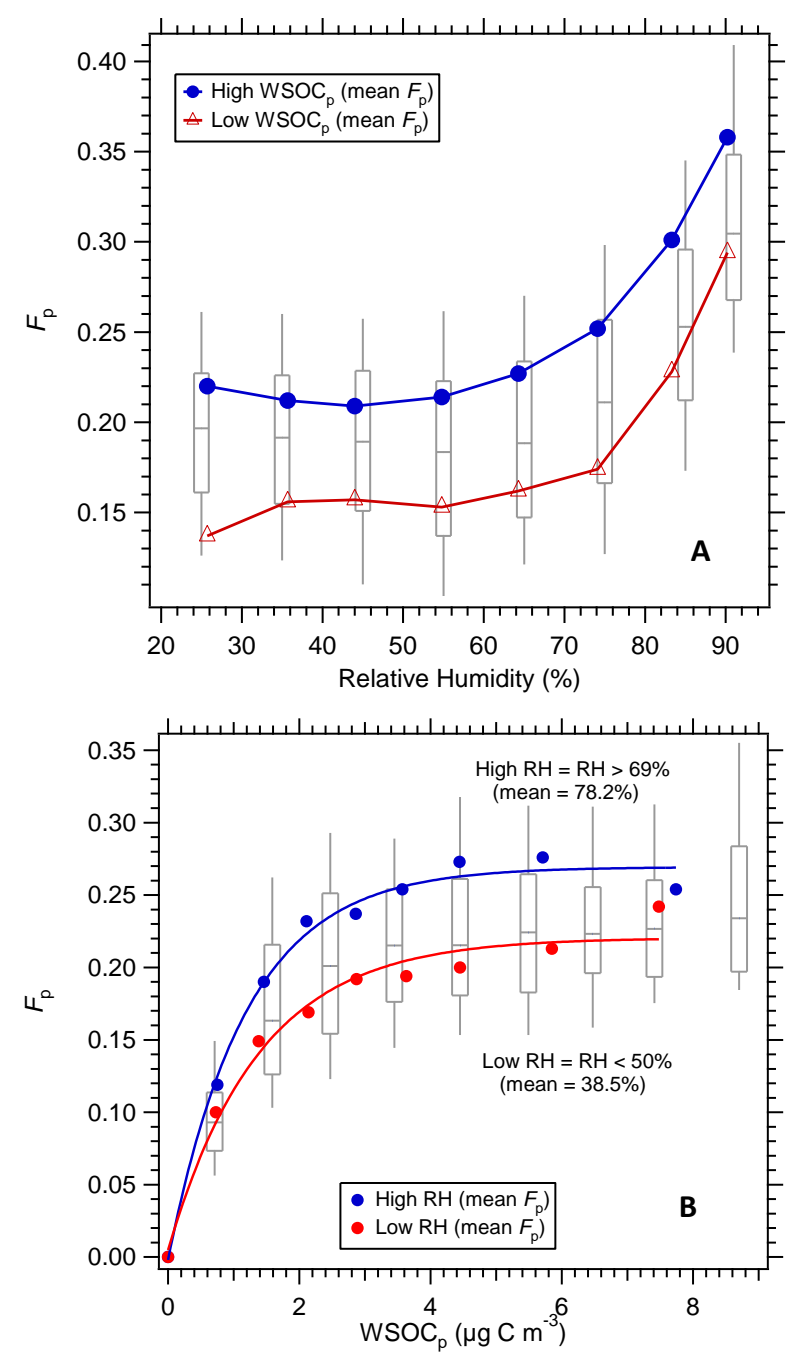

Fig. 9. WSOC partitioning as a function of $\mathrm{RH}$ and WSOC $_{p}$ concentration. Mean $F_{p}$ values versus $\mathrm{RH}$ for the highest (mean $\mathrm{WSOC}_{p}=5.3 \mu \mathrm{g} \mathrm{C} \mathrm{m}^{-3}$ ) and lowest (mean WSOC $_{p}=1.7 \mu \mathrm{g} \mathrm{Cm}^{-3}$ ) $35 \%$ of WSOC $_{p}$ concentrations (a). Mean $F_{p}$ values as a function $\mathrm{WSOC}_{p}$, segregated for high and low RH levels (b). The two data points at $(0,0)$ are not measured, but are based on the definition of $F_{p}$ (Eq. 1). Note that the curves only represent the central tendency and that there is considerable scatter about the mean (e.g., see Fig. 8b)

titioning: at the highest $\mathrm{RH}$ levels, the $\mathrm{WSOC}_{p}$ concentration still appears to be important (Fig. 9a, b). It indicates that $\mathrm{WSOC}_{p}$ and liquid water both somewhat independently contribute to WSOC gas/particle partitioning. As an example, the liquid water may affect absorption of the water-soluble gases, and the $\mathrm{WSOC}_{p}$ in the particle may influence the heterogeneous production of lower vapor pressure products. This qualitatively agrees with the conceptual models proposed by Kroll et al. (2007) and Chan et al. (2007), who suggest that condensed phase reactions may significantly affect 
the partitioning of SVOCs. Our results indicate that particlebound water is critical to enhanced SVOC partitioning and heterogeneous reaction. The types of heterogeneous reactions that take place in the liquid particle may account for the observed $F_{p}$ dependence on $\mathrm{WSOC}_{p}$. Secondly, because the curve for the much dryer particles (Fig. 9b) is essentially identical in shape to the wet particles, the overall partitioning mechanism appears to be similar throughout the $\mathrm{RH}$ range measured: the role of water is not just confined to $\mathrm{RH}>80 \%$ when particles rapidly absorb water and are very wet. In an ambient study, Khlystov et al. (2005) found that fine particles contained water at RH levels as low as $20-30 \%$ in the summer, compared to winter conditions in which fine particles were essentially dry below $\sim 60 \% \mathrm{RH}$. This water associated with fine particles, even at low abundances, may play an important role in heterogeneous chemistry leading to SOA formation.

There is substantial evidence from both laboratory and ambient studies suggesting that heterogeneous chemical reactions are important. Limbeck et al. (2003) observed enhanced isoprene SOA yields in the presence of acidic seed particles compared to yields using neutral seed particles. Kroll et al. (2007) found systematically higher SOA yields from aromatic VOCs in the presence of ammonium sulfate seed particles compared to experiments in which no seed particles were present. In experiments designed to simulate the chemistry occurring within cloud droplets, Altieri et al. (2008) observed the formation of oligomers from methylglyoxal, while Volkamer et al. (2009) observed SOA formation from acetylene in smog chamber experiments and attributed this to the formation of glyoxal and its subsequent uptake and reaction in particles. The results of Volkamer et al. (2009) included a linear correlation between SOA yields and aerosol liquid water concentrations, and an apparent effect of the existing organic aerosol composition on SOA yields as well, very similar to our findings. Perhaps the strongest proof of heterogeneous reactions is the presence of macromolecular organic compounds, or oligomers, as components of organic aerosol (e.g., Kalberer et al., 2006; Denkenberger et al., 2007). It is highly unlikely that oligomer formation occurs in the gas-phase, thus their presence in ambient particles confirms the occurrence of particlephase reactions as well. In relation to heterogeneous chemistry and the gas/particle partitioning of SVOCs, model simulations by Chan et al. (2007) demonstrate that the rates of SOA formation and the amount of SOA formed may be impacted by extensive heterogeneous reactions.

\subsection{General discussions/implications}

The above findings are based on measurements made over an extended period in the ambient atmosphere, hence they are relevant for regulatory and modeling applications. First, the observed $\mathrm{NO}_{\mathrm{x}}$ effect on $F_{p}$ could be important for control strategies of $\mathrm{O}_{3}$ and $\mathrm{PM}_{2.5}$, criteria pollutants which annually exceed EPA attainment limits in Atlanta (http://www.epa.gov/oar/oaqps/greenbk/). At high $\mathrm{NO}_{\mathrm{x}}$ levels, $F_{p}$ values were lower compared to those at low $\mathrm{NO}_{\mathrm{x}}$ levels, indicating that a higher fraction of the total WSOC was in the particle phase when $\mathrm{NO}_{\mathrm{x}}$ levels were low. Atlanta is a $\mathrm{NO}_{\mathrm{x}}$-limited environment, which suggests $\mathrm{NO}_{\mathrm{x}}$ reductions may be the most effective means of controlling $\mathrm{O}_{3}$ concentrations. The present results indicate that mitigating $\mathrm{O}_{3}$ concentrations through $\mathrm{NO}_{\mathrm{x}}$ reductions could increase $\mathrm{PM}_{2.5}$ mass concentrations. The importance of a $\mathrm{NO}_{\mathrm{x}}$ feedback on $\mathrm{PM}_{2.5}$ levels to $\mathrm{NO}_{\mathrm{x}}$ control is noteworthy and should be examined in more detail. (Note that decreasing $\mathrm{NO}_{\mathrm{x}}$ may also decrease SOA yields of certain compounds like sesquiterpens and large (C>12) alkanes (Kroll and Seinfeld, 2008), though the overall contribution of these compounds to the SOA budget is small in the Southeast. Thus, the feedback potential is likely greater with VOCs which exhibit inverse SOA yields with $\mathrm{NO}_{\mathrm{x}}$, though this question should be examined as well). There is evidence, however, that some other anthropogenic component may also influence $\mathrm{WSOC}_{p}$ production, signifying that there may be additional unidentified processes leading to SOA formation that could still restrict accurate prediction (Weber et al., 2007; Hennigan et al., 2008b).

The results presented in this study suggest that traditional SOA theory based solely on the partitioning of SVOCs as described by $K_{p}$ formulation (Eq. 3) may not be a suitable predictor of SOA in Atlanta. SOA partitioning theory predicts a strong relationship between $K_{p}$ (i.e., $F_{p}$ ) and OC (e.g., Odum et al., 1996) that was not seen in our ambient data. Though we note apparent differences between the application of theory based on the smog chamber results of Odum et al. (1996, 1997) and the present study, the smog chamber results, themselves, are actually in agreement with our observations. The absorbing organic medium, $M_{o}$, in those experiments is the SOA which was formed in the absence of any primary organic aerosol. It is thus likely that $M_{o}$, even the low-volatility components, is chemically similar to the SVOCs whose partitioning is enhanced by added organic aerosol since they arise from oxidation of the same VOCs. The real discrepancy arises when this theory is applied to the ambient atmosphere and the total organic aerosol is assumed to contribute wholly and equally to the absorptive partitioning of different SVOCs. Our results suggest that the chemical composition of $M_{o}$ is a critical factor in the partitioning process. This was apparent through the relationship observed between $F_{p}$ and $\mathrm{WSOC}_{p}$, though it differed from the relationships observed in chamber studies. $K_{p}$ theory predicts a strong effect of water on partitioning, and a strong $F_{p}$-RH effect was seen in the ambient results. However, $K_{p}$ theory also predicts that as the mass of liquid water exceeds $\mathrm{WSOC}_{p}$ (or OC), $F_{p}$ should become increasingly insensitive to $\mathrm{WSOC}_{p}$. This behavior was not observed in the ambient data, where the $\mathrm{WSOC}_{p}$ concentration remained an important factor for WSOC gas/particle partitioning even at the highest RH levels. A mechanism that incorporates both 
a partitioning of SVOCs to fine particle water and the reaction of organic compounds in the aqueous phase may better represent the partitioning that occurs in the Atlanta summer. This enhancement in particle phase partitioning, along with a photochemical mechanism, represent the major SOA formation pathways identified in the present study. A previous study has shown that these processes may be related (Hennigan et al., 2008b). In that study, periodic episodes of high correlation between $\mathrm{WSOC}_{p}$ and water vapor were observed throughout the summer. The co-emission of biogenic VOCs and water vapor from vegetation may have been responsible for the correlation. Subsequent oxidation of the biogenic VOCs and uptake of the water vapor to the aerosol phase upon ambient temperature changes may have increased SOA formation further, according to the mechanism suggested above.

Further ambient studies are required to investigate if the findings presented here apply to other locations as well, and identify the SVOCs and possible heterogeneous chemical mechanisms. Finally, an important issue not investigated is the reversibility of the observed partitioning, and how this varies with RH. There is evidence from an earlier study in Mexico City that a significant fraction (20 to 50\%) of the $\mathrm{WSOC}_{p}$ formed during a period of high RH $(\sim 90 \%)$ subsequently evaporated when RH dropped a few hours later (Hennigan et al., 2008c). A translation of results from Mexico City to Atlanta is uncertain, as Mexico City VOCs are predominantly anthropogenic (Volkamer et al., 2006) while Atlanta's are predominantly biogenic. Additionally, the processes affecting aerosol formation (i.e., emission profiles and photochemistry) may be highly different in the two cities as well. Nevertheless, the potential reversibility of the liquid water/heterogeneous reaction mechanism in Atlanta is a significant question and should be investigated.

\section{Conclusions}

We provide a detailed characterization of SOA partitioning in summertime Atlanta, a large urban center with substantial biogenic VOC emissions. WSOC in the particle and gas phases both had strong photochemical sources, while $\mathrm{WSOC}_{g}$ also appeared to have a unique nighttime source, possibly involving $\mathrm{NO}_{3}$ chemistry. Partitioning, analyzed through the fraction of total WSOC in the particle phase, $F_{p}$, was found to have no net dependence on temperature, though this was likely due to the emissions of precursor VOCs and the formation of WSOC (in the gas and particle phase), which both could have temperature dependences. $F_{p}$ was related to $\mathrm{NO}_{\mathrm{x}}$ concentrations, with higher $\mathrm{NO}_{\mathrm{x}}$ levels corresponding to lower values of $F_{p}$. Although not likely related to the partitioning process, this behavior could be attributed to the effect of $\mathrm{NO}_{\mathrm{x}}$ on the product distribution in VOC oxidation. In previous work, $F_{p}$ was shown to have a very strong dependence on relative humidity at RH levels above $70 \%$ due to the uptake of liquid water by fine particles. The current work also shows a strong partitioning dependence on the existing $\mathrm{WSOC}_{p}$ concentration, but not on the OC concentration, possibly indicating the importance of the chemical similarity between partitioning SVOCs and the absorbing aerosol phase, or the role of heterogeneous chemistry in SOA formation, or both. The relationship between $F_{p}$ and $\mathrm{WSOC}_{p}$ was present even at the highest RH levels, when the liquid water concentration was likely far greater than the $\mathrm{WSOC}_{p}$ concentration. Collectively, the results point to liquid-phase heterogeneous chemical reactions as another major SOA formation process and are remarkably similar to the recent chamber experiments of Volkamer et al. (2009).

Finally, the summertime data indicate that $\mathrm{WSOC}_{p}$ incorporated most, if not all, of the SOA in Atlanta. To our knowledge, this represents the first detailed characterization of SOA formation processes based on ambient data. Previous studies have described the gas/particle partitioning of the total SOA within a smog chamber, and previous ambient studies have reported on the partitioning of individual compounds. The results provide important insight into SOA formation and the gas/particle partitioning process beyond the current scientific understanding. Specifically, that fineparticle water and heterogeneous chemical reactions may be a significant mechanism for SOA formation in summertime Atlanta. This mechanism may also play an important role in other locations (e.g., Hennigan et al., 2008c), and may explain the systematic under-prediction of SOA by most models.

Acknowledgements. R. Weber thanks the National Science Foundation for their financial support through grant ATM-0802237. The generous financial gift from F. Cullen and L. Peck also made this work possible.

Edited by: A. S. H. Prevot

\section{References}

Altieri, K. E., Seitzinger, S. P., Carlton, A. G., Turpin, B. J., Klein, G. C., and Marshall, A. G.: Oligomers formed through in-cloud methylglyoxal reactions: Chemical composition, properties, and mechanisms investigated by ultra-high resolution FT-ICR mass spectrometry, Atmos. Environ., 42(7), 1476-1490, 2008

Anderson, C. H., Dibb, J. E., Griffin, R. J., Hagler, G. S. W., and Bergin, M. H.: Atmospheric water-soluble organic carbon measurements at Summit, Greenland, Atmos. Environ., 42(22), doi:10.1016/j.atmosenv.2008.03.06, 2008.

Bonn, B. and Moorgat, G. K.: New particle formation during aand b-pinene oxidation by $\mathrm{O} 3, \mathrm{OH}$ and $\mathrm{NO} 3$, and the influence of water vapour: particle size distribution studies, Atmos. Chem. Phys., 2, 183-196, 2002, http://www.atmos-chem-phys.net/2/183/2002/.

Bonn, B., Schuster, G., and Moortgat, G. K.: Influence of Water Vapor on the Process of New Particle Formation during Monoterpene Ozonolysis, J. Phys. Chem. A, 106(12), 2869-2881, 2002. 
Bowman, F. M. and Karamalegos, A. M.: Estimated effects of composition on secondary organic aerosol mass concentrations, Environ. Sci. Technol., 36(12), 2701-2707, 2002

Brown, S. S., deGouw, J. A., Warneke, C., Ryerson, T. B., Dubé, W. P., Atlas, E., Weber, R. J., Peltier, R. E., Neuman, J. A., Roberts, J. M., Swanson, A., Flocke, F., McKeen, S. A., Brioude, J., Sommariva, R., Trainer, M., Fehsenfeld, F. C., and Ravishankara, A. R.: Nocturnal isoprene oxidation over the Northeast United States in summer and its impact on reactive nitrogen partitioning and secondary organic aerosol, Atmos. Chem. Phys., 9, 30273042, 2009,

http://www.atmos-chem-phys.net/9/3027/2009/.

Chan, A. W. H., Kroll, J. H., Ng, N. L., and Seinfeld, J. H.: Kinetic modeling of secondary organic aerosol formation: effects of particle- and gas-phase reactions of semivolatile products, Atmos. Chem. Phys., 7, 4135-4147, 2007,

http://www.atmos-chem-phys.net/7/4135/2007/.

Chang, E. I. and Pankow, J. F.: Organic particulate matter formation at varying relative humidity using surrogate secondary and primary organic compounds with activity corrections in the condensed phase obtained using a method based on the Wilson equation, Atmos. Chem. Phys. Discuss., 8, 995-1039, 2008, http://www.atmos-chem-phys-discuss.net/8/995/2008/.

Chu, S.-H., Paisie, J. W., and Jang, B. W.-L.: PM data analysis a comparison of two urban areas: Fresno and Atlanta, Atmos. Environ., 38, 3155-3164, 2004.

Cocker, D. R., Clegg, S. L., Flagan, R. C., and Seinfeld, J. H.: The effect of water on gas-particle partitioning of secondary organic aerosol, Part I: alpha-pinene/ozone system, Atmos. Environ., 35(35), 6049-6072, 2001a.

Cocker, D. R., Mader, B. T., Kalberer, M., Flagan, R. C., and Seinfeld, J. H.: The effect of water on gas-particle partitioning of secondary organic aerosol: II. m-xylene and 1,3,5-trimethylbenzene photooxidation systems, Atmos. Environ., 35(35), 6073-6085, $2001 b$.

Cofer, W. R. and Edahl, R. A.: A new technique for collection, concentration and determination of gaseous tropospheric formaldehyde, Atmos. Environ., 20(5), 979-984, 1986.

Cornbleet, P. J. and Gochman, N.: Incorrect least-squares regression coefficients in method-comparison analysis, Clin. Chem., 25, 432-438, 1979.

de Gouw, J. A., Middlebrook, A. M., Warneke, C., Goldan, P. D., Kuster, W. C., Roberts, J. M., Fehsenfeld, F. C., Worsnop, D. R., Canagaratna, M. R., Pszenny, A. A. P., Keene, W. C., Marchewka, M., Bertman, S. B., and Bates, T. S.: Budget of organic carbon in a polluted atmosphere: Results from the New England Air Quality Study in 2002, J. Geophys. Res.-Atmos., 110(D16), doi:10.1029/2004JD005623, 2005.

Denkenberger, K. A., Moffet, R. C., Holecek, J. C., Rebotier, T. P., Prather, K. A.: Real-time, single-particle measurements of oligomers in aged ambient aerosol particles, Environ. Sci. Technol., 41(15), 5439-5446, 2007.

Edney, E. O., Driscoll, D. J., Speer, R. E., Weathers, W. S., Kleindienst, T. E., Li, W., and Smith, D. F.: Impact of aerosol liquid water on secondary organic aerosol yields of irradiated toluene/propylene/NOx/(NH4)(2) SO4/air mixtures, Atmos. Environ., 34(23), 3907-3919, 2000.

Environmental Protection Agency, National Emissions Inventory, www.epa.gov/ttn/chief/net/2002inventory.html, 2002.
Favez, O., Sciare, J., Cachier, H., Alfaro, S. C., and Abdelwahab, M. M.: Significant formation of water-insoluble secondary organic aerosols in semi-arid urban environment, Geophys. Res. Lett., 35(15), 2008.

Fisseha, R., Dommen, J., Gaeggeler, K., Weingartner, E., Samburova, V., Kalberer, M., and Baltensperger, U.: Online gas and aerosol measurement of water soluble carboxylic acids in Zurich, J. Geophys. Res.-Atmos., 111(D12), 2006.

Fountoukis, C. and Nenes, A.: ISORROPIA II: a computationally efficient thermodynamic equilibrium model for $\mathrm{K}^{+}$$\mathrm{Ca}^{2+}-\mathrm{Mg}^{2+}-\mathrm{NH}_{4}^{+}-\mathrm{Na}^{+}-\mathrm{SO}_{4}^{2-}-\mathrm{NO}_{3}^{-}-\mathrm{Cl}^{-}-\mathrm{H}_{2} \mathrm{O}$ aerosols, Atmos. Chem. Phys., 7, 4639-4659, 2007, http://www.atmos-chem-phys.net/7/4639/2007/.

Georgia Department of Natural Resources Ambient Monitoring Network, http://www.georgiaepd.org/air/amp/, 2008.

Goldstein, A. H. and Galbally, I. E.: Known and unexplored organic constituents in the earth's atmosphere, Environ. Sci. Technol., 41(5), 1514-1521, 2007.

Griffin, R. J., Cocker, D. R., Flagan, R. C., and Seinfeld, J. H.: Organic aerosol formation from the oxidation of biogenic hydrocarbons, J. Geophys. Res.-Atmos., 104(D3), 3555-3567, 1999.

Guenther, A., Zimmerman, P., and Wildermuth, M.: Natural volatile organic compound emission rate estimates for United States woodland landscapes, Atmos. Environ., 28(6), 1197-1210, 1994.

Hakola, H., Laurila, T., Rinne, J., and Puhto, K.: The ambient concentrations of biogenic hydrocarbons at a northern European, boreal site, Atmos. Environ, 34(29-30), 4971-4982, 2000.

Hallquist, M., Wangberg, I., Ljungstrom, E., Barnes, I., and Becker, K. H.: Aerosol and product yields from NO3 radical-initiated oxidation of selected monoterpenes, Environ. Sci. Technol., 33(4), 553-559, 1999.

Hennigan, C. J., Bergin , M. H., Dibb, J. E. , and Weber, R. J.: Enhanced secondary organic aerosol formation due to water uptake by fine particles, Geophys. Res. Lett., 35, L18801, doi:10.1029/2008GL035046, 2008a.

Hennigan, C. J., Bergin, M. H., and Weber, R. J.: Correlations between water-soluble organic aerosol and water vapor: A synergistic effect from biogenic emissions?, Environ. Sci. Technol., 42(24), 9079-9085, 2008b.

Hennigan, C. J., Sullivan, A. P., Fountoukis, C. I., Nenes, A., Hecobian, A., Vargas, O., Peltier, R. E., Case Hanks, A. T., Huey, L. G., Lefer, B. L., Russell, A. G., and Weber, R. J.: On the volatility and production mechanisms of newly formed nitrate and water soluble organic aerosol in Mexico City, Atmos. Chem. Phys., 8, 3761-3768, 2008c,

http://www.atmos-chem-phys.net/8/3761/2008/.

Hoffmann, T., Odum, J. R., Bowman, F., Collins, D., Klockow, D., Flagan, R. C., Seinfeld, J. H.: Xb, Formation of organic aerosols from the oxidation of biogenic hydrocarbons, J. Atmos. Chem., 26(2), 189-222, 1997.

Janson, R., Rosman, K., Karlsson, A., and Hansson, H. C.: Biogenic emissions and gaseous precursors to forest aerosols, Tellus. B., 53(4), 423-440, 2001.

Jonsson, A. M.; Hallquist, M.; Ljungstrom, E., Impact of humidity on the ozone initiated oxidation of limonene, Delta(3)-carene, and alpha-pinene, Environ. Sci. Technol., 40(1), 188-194, 2006.

Kalberer, M. Sax, M., and Samburova, V.: Molecular size evolution of oligomers in organic aerosols collected in urban atmospheres and generated in a smog chamber, Environ. Sci. Technol., 40(19), 
5917-5922, 2006.

Khlystov, A., Stanier, C. O., Takahama, S., and Pandis, S. N.: Water content of ambient aerosol during the Pittsburgh Air Quality Study, J. Geophys. Res., 110, D07S10, doi:10.1029/2004JD004651, 2005.

Kroll, J. H.; Seinfeld, J. H., Chemistry of secondary organic aerosol: Formation and evolution of low-volatility organics in the atmosphere, Atmos. Environ., 42(16), 3593-3624, 2008.

Kroll, J. H., Chan, A. W. H., Ng, N. L., Flagan, R. C., and Seinfeld, J. H.: Reactions of semivolatile organics and their effects on secondary organic aerosol formation, Environ. Sci. Technol., 41(10), 3545-3550, 2007.

Kroll, J. H., Ng, N. L., Murphy, S. M., Flagan, R. C., and Seinfeld, J. H.: Secondary organic aerosol formation from isoprene photooxidation, Environ. Sci. Technol., 40(6), 1869-1877, 2006.

Lanz, V. A., Alfarra, M. R., Baltensperger, U., Buchmann, B., Hueglin, C., and Prvt, A. S. H.: Source apportionment of submicron organic aerosols at an urban site by factor analytical modelling of aerosol mass spectra, Atmos. Chem. Phys., 7, 15031522, 2007,

http://www.atmos-chem-phys.net/7/1503/2007/.

Limbeck, A.; Kulmala, M.; Puxbaum, H., Secondary organic aerosol formation in the atmosphere via heterogeneous reaction of gaseous isoprene on acidic particles. Geophys. Res. Lett., 30(19), doi:10.1029/2003GL017738, 2003.

Malm, W. C. and Day, D. E.: Estimates of aerosol species scattering characteristics as a function of relative humidity, Atmos. Environ., 35(16), 2845-2860, 2001.

Marple, V. A., Rubow, K. L., and Behm, S. M.: A microorifice uniform deposit impactor (MOUDI) - description, calibration, and use, Aerosol. Sci Tech., 14(4), 434-446, 1991.

Matsunaga, S. N., Kato, S., Yoshino, A., Greenberg, J. P., Kajii, Y., and Guenther, A. B.: Gas-aerosol partitioning of semi volatile carbonyls in polluted atmosphere in Hachioji, Tokyo, Geophys. Res. Lett., 32(11), 2005.

Miyazaki, Y., Kondo, Y., Takegawa, N., Komazaki, Y., Fukuda, M., Kawamura, K., Mochida, M., Okuzawa, K., and Weber, R. J.: Time-resolved measurements of water-soluble organic carbon in Tokyo, J. Geophys. Res.-Atmos., 111(D23), doi:10.1029/2006JD007125, 2006.

Nenes, A., Pandis, S. N., and Pilinis, C.: ISORROPIA: A new thermodynamic equilibrium model for multiphase multicomponent inorganic aerosols, Aquat. Geochem., 4(1), 123-152, 1998.

Ng, N. L., Chhabra, P. S., Chan, A. W. H., Surratt, J. D., Kroll, J. H., Kwan, A. J., McCabe, D. C., Wennberg, P. O., Sorooshian, A., Murphy, S. M., Dalleska, N. F., Flagan, R. C., and Seinfeld, J. H.: Effect of $\mathrm{NO}_{\mathrm{x}}$ level on secondary organic aerosol (SOA) formation from the photooxidation of terpenes, Atmos. Chem. Phys., 7, 5159-5174, 2007a,

http://www.atmos-chem-phys.net/7/5159/2007/.

Ng, N. L., Kroll, J. H., Chan, A. W. H., Chhabra, P. S., Flagan, R. C., and Seinfeld, J. H.: Secondary organic aerosol formation from $m$-xylene, toluene, and benzene, Atmos. Chem. Phys., 7, 3909-3922, 2007b,

http://www.atmos-chem-phys.net/7/3909/2007/.

Ng, N. L., Kwan, A. J., Surratt, J. D., Chan, A. W. H., Chhabra, P. S., Sorooshian, A., Pye, H. O. T., Crounse, J. D., Wennberg, P. O., Flagan, R. C., and Seinfeld, J. H.: Secondary organic aerosol (SOA) formation from reaction of isoprene with nitrate radicals
$\left(\mathrm{NO}_{3}\right)$, Atmos. Chem. Phys., 8, 4117-4140, 2008 , http://www.atmos-chem-phys.net/8/4117/2008/.

NIOSH: Elemental Carbon (Diesel Particulate): Method 5040, in: NIOSH Manual of Analytical Methods, edited by: Eller, P. M. and Cassinelli, M. E., National Institute for Occupational Safety and Health, Cincinnati, USA, 1996.

Odum, J. R., Jungkamp, T. P. W., Griffin, R. J., Flagan, R. C., and Seinfeld, J. H.: The atmospheric aerosol-forming potential of whole gasoline vapor, Science, 276(5309), 96-99, 1997.

Odum, J. R., Hoffmann, T., Bowman, F., Collins, D., Flagan, R. C., and Seinfeld, J. H.: Va, Gas/particle partitioning and secondary organic aerosol yields, Environ. Sci. Technol., 30(8), 2580-2585, 1996.

Orsini, D. A., Ma, Y. L., Sullivan, A., Sierau, B., Baumann, K., Weber, R. J.: Refinements to the particle-into-liquid sampler (PILS) for ground and airborne measurements of water soluble aerosol composition, Atmos. Environ., 37(9-10), 1243-1259, 2003.

Pandis, S. N., Paulson, S. E., Seinfeld, J. H., and Flagan, R. C.: Aerosol formation in the photooxidation of isoprene and betapinene, Atmos. Environ. A-Gen., 25(5-6), 997-1008.1991

Pankow, J. F.: An absorption model of the gas aerosol partitioning involved in the formation of secondary organic aerosol, Atmos. Environ., 28(2), 189-193, 1994.

Pankow, J. F. and Bidleman, T. F.: Effects of temperature, TSP and percent nonexchangeable material in determining the gas particle partitioning of organic compounds, Atmos. Environ. A-Gen., 25(10), 2241-2249, 1991.

Peltier, R. E., Weber, R. J., Sullivan, A. P.: Investigating a liquidbased method for online organic carbon detection in atmospheric particles, Aerosol. Sci. Tech., 41(12), 1117-1127, 2007.

Presto, A. A., Hartz, K. E. H., and Donahue, N. M.: Secondary organic aerosol production from terpene ozonolysis, 2. Effect of $\mathrm{NO}_{\mathrm{x}}$ concentration, Environ. Sci. Technol., 39(18), 7046-7054, 2005.

Pun, B. K. and Seigneur, C.: Investigative modeling of new pathways for secondary organic aerosol formation, Atmos. Chem. Phys., 7, 2199-2216, 2007, http://www.atmos-chem-phys.net/7/2199/2007/.

Saxena, P. and Hildemann, L. M.: Water-soluble organics in atmospheric particles: A critical review of the literature and application of thermodynamics to identify candidate compounds, J. Atmos. Chem., 24(1), 57-109, 1996.

Seinfeld, J. H., Erdakos, G. B., Asher, W. E., and Pankow, J. F. Modeling the formation of secondary organic aerosol (SOA). 2. The predicted effects of relative humidity on aerosol formation in the alpha-pinene-, beta-pinene-, sabinene-, Delta(3)-Carene-, and cyclohexene-ozone systems, Environ. Sci. Technol., 35(9), 1806-1817, 2001

Seinfeld, J. H. and Pandis, S. N.: Atmospheric Chemistry and Physics, From Air Pollution to Climate Change, John Wiley \& Sons, New York, NY, USA, 1998.

Simon, V., Clement, B., Riba, M. L., and Torres, L.: The LANDES experiment - Monoterpenes emitted from the maritime pine, J. Geophys. Res.-Atmos., 99(D8), 16501-16510, 1994.

Song, C., Zaveri, R. A., Alexander, M. L., Thornton, J. A., Madronich, S., Ortega, J. V., Zelenyuk, A., Yu, X.-Y., Laskin, A., and Maughan, D. A.: Effect of hydrophobic primary organic aerosols on secondary organic aerosol formation from ozonolysis of alpha-pinene, Geophys. Res. Lett., 34, L20803, 
doi:10.1029/2007GL030720, 2007.

Spaulding, R. S., Talbot, R. W., and Charles, M. J.: Optimization of a mist chamber (cofer scrubber) for sampling water-soluble organics in air, Environ. Sci. Technol., 36(8), 1798-1808, 2002.

Stark, H., Brown, S. S., Goldan, P. D., Aldener, M., Kuster, W. C., Jakoubek, R., Fehsenfeld, F. C., Meagher, J., Bates, T. S., and Ravishankara, A. R.: Influence of nitrate radical on the oxidation of dimethyl sulfide in a polluted marine environment, J. Geophys. Res., 112, D10S10, doi:10.1029/2006JD007669, 2007.

Stenby, C., Pöschl, U., von Hessberg, P., Bilde, M., Nielsen, O. J., and Moortgat, G. K.: Temperature and humidity dependence of secondary organic aerosol yield from the ozonolysis of $\beta$-pinene, Atmos. Chem. Phys. Discuss., 7, 2091-2132, 2007, http://www.atmos-chem-phys-discuss.net/7/2091/2007/.

Sullivan, A. P., Peltier, R. E., Brock, C. A., de Gouw, J. A., Holloway, J. S., Warneke, C., Wollny, A. G., Weber, R. J.: Airborne measurements of carbonaceous aerosol soluble in water over northeastern United States: Method development and an investigation into water-soluble organic carbon sources, J. Geophys. Res.-Atmos., 111(D23), D05314, doi:10.1029/2005JD006485, 2006.

Sullivan, A. and Weber, R. J.: Chemical characterization of the ambient organic aerosol soluble in water Part 2: Isolation of acid, neutral, and basic fractions by modified size exclusion chromatography, J. Geophys. Res., 111(D5), D05315, 10.1029/2005JD006486, 2006.

Sullivan, A. P., Weber, R. J., Clements, A. L., Turner, J. R., Bae, M. S., and Schauer, J. J.: A method for on-line measurement of water-soluble organic carbon in ambient aerosol particles: Results from an urban site, Geophys. Res. Lett., 31(13), L13105, doi:10.1029/2004GL019681, 2004

Takekawa, H., Minoura, H., and Yamazaki, S.: Temperature dependence of secondary organic aerosol formation by photo-oxidation of hydrocarbons, Atmos. Environ., 37(24), 3413-3424, 2003.

Tingey, D. T., Manning, M., Grothaus, L. C., and Burns, W. F.: Influence of light and temperature on monoterpene emission rates from slash pine, Plant. Physiol., 65(5), 797-801, 1980.

Tingey, D. T., Manning, M., Grothaus, L. C., and Burns, W. F.: Influence of light and temperature on isoprene emission rates from live oak, Physiol. Plantarum., 47(2), 112-118, 1979.
Tsigaridis, K., Lathire, J., Kanakidou, M., and Hauglustaine, D. A.: Naturally driven variability in the global secondary organic aerosol over a decade, Atmos. Chem. Phys., 5, 1891-1904, 2005, http://www.atmos-chem-phys.net/5/1891/2005/.

Volkamer, R., Ziemann, P. J., and Molina, M. J.: Secondary Organic Aerosol Formation from Acetylene $\left(\mathrm{C}_{2} \mathrm{H}_{2}\right)$ : seed effect on SOA yields due to organic photochemistry in the aerosol aqueous phase, Atmos. Chem. Phys., 9, 1907-1928, 2009, http://www.atmos-chem-phys.net/9/1907/2009/.

Volkamer, R., Jimenez, J. L., San Martini, F., Dzepina, K., Zhang, Q., Salcedo, D., Molina, L. T., Worsnop, D. R., and Molina, M. J.: Secondary organic aerosol formation from anthropogenic air pollution: Rapid and higher than expected, Geophys. Res. Lett., 33(17), L17811, doi:10.1029/2006GL026899, 2006.

Warneke, C., de Gouw, J. A., Goldan, P. D., Kuster, W. C., Williams, E. J., Lerner, B. M., Jakoubek, R., Brown, S. S., Stark, H., Aldener, M., Ravishankara, A. R., Roberts, J. M., Marchewka, M., Bertman, S., Sueper, D. T., McKeen, S. A., Meagher, J. F., and Fehsenfeld, F. C.: Comparison of daytime and nighttime oxidation of biogenic and anthropogenic VOCs along the New England coast in summer during New England Air Quality Study 2002, J. Geophys. Res., 109, D10309, doi:10.1029/2003JD004424, 2004.

Weber, R. J., Sullivan, A. P., Peltier, R. E., Russell, A., Yan, B., Zheng, M., de Gouw, J., Warneke, C., Brock, C., Holloway, J. S., Atlas, E. L., and Edgerton, E.: A study of secondary organic aerosol formation in the anthropogenic-influenced southeastern United States, J. Geophys. Res.-Atmos., 112(D13), D13302, doi:10.1029/2007JD008408, 2007.

Weber, R., Orsini, D., Bergin, M., Kiang, C. S., Chang, M., John, J. S., Carrico, C. M., Lee, Y. N., Dasgupta, P., Slanina, J., Turpin, B., Edgerton, E., Hering, S., Allen, G., Solomon, P., and Chameides, W.: Short-Term Temporal Variation, in: $\mathrm{PM}_{2.5}$ Mass And Chemical Composition During The Atlanta Supersite Experiment, 1999, J. Air. Waste. Manage., 53, 84-91, 2003. 